Published in final edited form as:

Prog Retin Eye Res. 2013 May ; 34: 49-77. doi:10.1016/j.preteyeres.2012.11.002.

\title{
Macular telangiectasia type 2
}

\author{
Peter Charbel Issa ${ }^{a,{ }^{*}, 1}$, Mark C. Gillies $^{\mathrm{b}, 1}$, Emily Y. Chew ${ }^{\mathrm{c}, 1}$, Alan C. Birdd ${ }^{\mathrm{d}, 1}$, Tjebo F.C. \\ Heeren $^{\mathrm{a}, 1}$, Tunde Peto ${ }^{\mathrm{d}, 1}$, Frank G. Holz ${ }^{\mathrm{a}, 1}$, and Hendrik P.N. Scholle ${ }^{*}, 1$ \\ aDepartment of Ophthalmology, University of Bonn, Ernst-Abbe-Str. 2, 53127 Bonn, Germany \\ bDepartment of Clinical Ophthalmology, Save Sight Institute, University of Sydney, Australia \\ 'Division of Epidemiology and Clinical Applications, National Eye Institute, National Institutes of \\ Health, Bethesda, MD, USA
}

dNIHR Biomedical Research Centre for Ophthalmology, Moorfields Eye Hospital NHS Foundation Trust and UCL Institute of Ophthalmology, London, UK

eWilmer Eye Institute, Johns Hopkins University School of Medicine, 748 Maumenee Building, 1800 Orleans Street, Baltimore, MD 21287-9277, USA

\section{Abstract}

Macular telangiectasia type 2 is a bilateral disease of unknown cause with characteristic alterations of the macular capillary network and neurosensory atrophy. Its prevalence may be underestimated and has recently been shown to be as high as $0.1 \%$ in persons 40 years and older. Biomicroscopy may show reduced retinal transparency, crystalline deposits, mildly ectatic capillaries, blunted venules, retinal pigment plaques, foveal atrophy, and neovascular complexes. Fluorescein angiography shows telangiectatic capillaries predominantly temporal to the foveola in the early phase and a diffuse hyperfluorescence in the late phase. High-resolution optical coherence tomography (OCT) may reveal disruption of the photoreceptor inner segment-outer segment border, hyporeflective cavities at the level of the inner or outer retina, and atrophy of the retina in later stages. Macular telangiectasia type 2 shows a unique depletion of the macular pigment in the central retina and recent therapeutic trials showed that such depleted areas cannot re-accumulate lutein and zeaxanthin after oral supplementation. There have been various therapeutic approaches with limited or no efficacy. Recent clinical trials with compounds that block vascular endothelial growth factor (VEGF) have established the role of VEGF in the pathophysiology of the disease, but have not shown significant efficacy, at least for the nonneovascular disease stages. Recent progress in structure-function correlation may help to develop surrogate outcome measures for future clinical trials.

In this review article, we summarize the current knowledge on macular telangiectasia type 2, including the epidemiology, the genetics, the clinical findings, the staging and the differential diagnosis of the disease. Findings using retinal imaging are discussed, including fluorescein angiography, OCT, adaptive optics imaging, confocal scanning laser ophthalmoscopy, and fundus autofluorescence, as are the findings using visual function testing including visual acuity and fundus-controlled microperimetry. We provide an overview of the therapeutic approaches for both

\footnotetext{
(C) 2012 Elsevier Ltd. All rights reserved

"Corresponding author. Tel.: +1 410614 6908; fax: +1 410614 2186. peter.issa@ ukb.uni-bonn.de (P. Charbel Issa). *Corresponding author. Tel.: +49 228287 15505; fax: +49 228287 15603. hscholl1 @jhmi.edu (H.P.N. Scholl)..

${ }_{1}^{1}$ Percentage of work contributed by each author in the production of the manuscript is as follows: Peter Charbel Issa: $45 \%$; Hendrik P.N. Scholl: 20\%; Mark C. Gillies: 5\%; Emily Y. Chew: 5\%; Alan C. Bird: 5\%; Tjebo F.C. Heeren: 10\%; Tunde Peto: 5\%; Frank G. Holz: $5 \%$.
}

Appendix A. Supplementary data Supplementary material associated with this article can be found, in the online version, at http:// dx.doi.org/10.1016/j.preteyeres.2012.11.002. 
non-neovascular and neovascular disease stages and provide a perspective of future directions including animal models and potential therapeutic approaches.

\section{Keywords}

Macular telangiectasia; Macular pigment; Phenotype; Treatment; Müller cell; Imaging; Vascular endothelial growth factor (VEGF); Optical coherence tomography (OCT); Neurodegeneration; Retina

\section{Introduction}

Macular telangiectasia (MacTel) type 2 is a bilateral disease of unknown cause with characteristic alterations of the macular capillary network and neurosensory atrophy. The disease manifests initially temporal to the foveal center, but may later encompass an oval area with a radius of about $6^{\circ}$ horizontally and $5^{\circ}$ vertically centered on the foveola. Symptoms typically start in the fifth or sixth decade of life. Some patients have a positive family history. Possibly due to low disease awareness, both amongst clinicians and patients, the diagnosis of MacTel is often delayed. It may also be misdiagnosed as age-related macular degeneration in the presence of neovascularization.

Beginning in 2005, the Macular Telangiectasia Project (“MacTel Project'; http:// www.mactelresearch.org) has initiated major research activity on MacTel type 2. In an effort involving a number of clinical centers and basic science laboratories, this privately funded project aims to develop a better understanding of the clinical features and natural history of the disease, to elucidate a genetic association, to identify animal models which may improve the understanding of intrinsic pathogenetic mechanisms, and ultimately, to identify and test potential treatments.

This increased research interest in MacTel type 2 has helped to gain new insights in the disease in several ways. Characteristic phenotypic findings have been identified using various imaging techniques that now allow an improved clinical differentiation of this entity from other retinal diseases. Moreover, the description of affected but asymptomatic family members of patients together with the higher than expected prevalence in population based studies should clearly increase the awareness of the disease.

In this review, updated phenotypic characterization of MacTel type 2 including morphologic data (derived from retinal imaging and histopathology), data on retinal dysfunction, epidemiology, genetics, together with a review of likely pathogenic mechanisms and attempted treatments are provided.

\section{Terminology}

A variety of terms have been used for MacTel type 2. The first description of the disease was likely a short report of Donald Gass on "bilateral paracentral capillary telangiectasia of unknown cause" (Gass, 1977) followed by a case series on "focal parafoveal retinal telangiectasis" (Hutton et al., 1978) which further characterized the disease as a distinct clinical entity with familial occurrence. The term "retinal telangiectasis" was introduced earlier by Reese to describe various retinopathies characterized by dilated and incompetent vessels (Reese, 1956). However, his case series, as well as a later fluorescein angiographic study on retinal telangiectasis (Gass, 1968), did not include MacTel type 2.

In a revised version of an earlier publication (Gass and Oyakawa, 1982), Gass and Blodi classified various disease entities with ectatic retinal vessels of unknown origin at the 
posterior pole (Gass and Blodi, 1993). Based on phenotypic differences, they identified three distinct groups (and additional sub-forms) of "idiopathic juxtafoveolar retinal telangiectasis" (Table 1) that were suggested to differ in their pathophysiology. These idiopathic diseases should be distinguished from similar vascular alterations that may be caused by diseases such as retinal vein occlusion, vasculitis, diabetes, carotid occlusive disease or radiation therapy. Group 2A of Gass and Blodi's revised classification is equivalent to MacTel type 2.

To characterize the localization of the vascular alterations in MacTel type 2, authors later used terms such as para-, peri-, and juxta-foveal or -foveolar. According to Hogan et al., the fovea covers the central $\sim 1.5 \mathrm{~mm}$ and the foveola the central $\sim 200 \mu \mathrm{m}$ of the retina (Hogan et al., 1971). A terminology implying "close to" (para-, peri-, juxta-) as topographic reference would limit the disease process to an area in direct vicinity to the respective anatomical landmark, excluding the fovea or foveola. However, the neurosensory disease process in MacTel type 2 involves the foveal center and capillaries directly bordering the foveal avascular zone.

The macula as a topographic reference is a more comprehensive descriptive term for the localization of retinal alterations in MacTel type 2. Although the macular area is not defined consistently in the literature, it would refer to a central retinal area including the foveal center. Consequently, recent publications used the term "macular telangiectasia". The abbreviation "MacTel" was chosen as the acronym for the Macular Telangiectasia Project. Despite the increasing evidence for a secondary origin of the vascular alterations, we suggest to keep this descriptive nomenclature, at least for the time being. It is furthermore suggested that the categorization into different groups (Gass and Blodi, 1993; Gass and Oyakawa, 1982) is renamed as "types", in order to emphasize the phenotypic and pathophysiologic difference. A new terminology might be considered once the various phenotypes presenting with idiopathic macular telangiectasia have been better characterized, and once there is more clarity about the pathophysiology and the genetic background of the diseases.

\section{Epidemiology}

The prevalence of MacTel type 2 has so far been analyzed in four population-based studies from three continents. Two populations included mainly Caucasians from the United States and Australia, and two others included Africans from Kenya and Nigeria. Data from the Beaver Dam study in the US (cohort: 4790 people, $43-86$ years of age) suggest a prevalence of $0.1 \%$ in the age group analyzed based on grading from stereoscopic mydriatic fundus photographs (Klein et al., 2010). Data from the Melbourne Collaborative Cohort Study in Australia suggested a lower prevalence, estimated to range from 0.004 to $0.022 \%$ based on non-mydriatic digital macular images (just over 22,000 participants, mean age of 65 years) (Aung et al., 2010). As noted by Klein et al., this lower prevalence estimate might be due to different methodology in the grading of the fundus photographs. The Beaver Dam Eye Study fundus photographs were entirely re-assessed while the Australian images were only graded specifically for MacTel type 2 if a previous grading had suggested at least one feature of the disease (Klein et al., 2010). Analysis of digital non-mydriatic fundus images from Kenya and Nigeria (together 8599 participants) suggested a prevalence of 0.06 in both countries (95\% confidence interval $0.02-0.21 \%$ and $0.01-0.17 \%$, respectively), with an estimated combined rate of 0.06 (95\% confidence interval 0.02-0.14\%) (Sallo et al., 2012a). Similar to the analysis from the Beaver Dam Eye Study, all images were re-assessed for the presence of MacTel type 2.

Notably, the true prevalence is likely to be underestimated in all four analyzed populations due to a grading based solely on color fundus images. More advanced imaging technologies 
were not used, such as fluorescein angiography, optical coherence tomography or confocal scanning laser ophthalmoscopy imaging including fundus autofluorescence, that have been shown to be more sensitive in detecting early and/or asymptomatic disease stages of MacTel type 2 (Gillies et al., 2009).

Gender distribution was without a clear predilection in the large cohort $(n=92)$ reported by Gass and Blodi (1993). The proportion of women in the baseline report of the MacTel multicenter study $(n=310)$ is $64 \%$ (Clemons et al., 2010). The mean age of patients at enrolment in the MacTel study was 61 years (SD, \pm 9 years) and mean age at diagnosis was 57 (SD, \pm 9 years) (Clemons et al., 2010). Currently, no reliable data are available on the time of onset of symptoms.

\section{Inheritance and genetics}

The bilaterality of the disease together with the occurrence in monozygotic twins (Gillies et al., 2009; Hannan et al., 2007; Menchini et al., 2000; Siddiqui and Fekrat, 2005) as well as in siblings and families (Chew et al., 1986; Delaere et al., 2011; Gass and Blodi, 1993; Gillies et al., 2009; Hutton et al., 1978; Isaacs and McAllister, 1996; Oh and Park, 1999; Parmalee et al., 2012) suggests genetic factors in the pathogenesis of MacTel type 2. Vertical transmission in families suggests a dominant inheritance. As part of the MacTel project, 17 pedigrees with multiple affected family members were identified out of a large cohort of patients with MacTel type 2, which were consistent with an autosomal dominant segregation with reduced penetrance (Parmalee et al., 2012). Moreover, there appears to be variable expressivity as suggested by the different clinical disease stage of a monozygotic twin pair (Gillies et al., 2009). Environmental and epigenetic factors, and/or gene-geneinteractions thus may also play a role in the development of the disease phenotype.

So far, candidate-gene screening approaches to identify a genetic defect responsible for MacTel type 2 have been unsuccessful (Parmalee et al., 2010; Szental et al., 2010). Subsequent genome-wide linkage analysis identified a single peak on chromosome 1 at 1q41-42 (Parmalee et al., 2012). However, sequencing of 14 candidate genes within the $15.6 \mathrm{Mb}$ region did not identify causal variants. Certainly, discovery of a disease-causing genetic defect would have an impact on further research on MacTel type 2, particularly on identification and understanding of pathogenetic pathways, new therapeutic approaches, and the development of relevant animal models.

\section{Clinical findings}

Since funduscopic findings early in the disease course may be very subtle, thorough biomicroscopy is necessary. Bilaterality is characteristic for MacTel type 2. Although biomicroscopic features are usually rather symmetric, they may be more advanced in one eye than the other (Clemons et al., 2010). Therefore, the few reported unilateral cases may exhibit an asymmetric disease with very mild and hardly discernible changes in the apparently unaffected eye (Bruè et al., 2011). The retinal alterations typical for MacTel type 2 usually begin in a temporal paracentral area. They may eventually affect a characteristic oval region within about one disc diameter eccentricity from the foveal center, where the horizontal diameter is larger than the vertical diameter. The horizontal raphe is not respected by the disease process. Despite the angiographic leakage, there is generally no biomicroscopic or angiographic evidence of prominent cystoid macular edema.

In case of a circular involvement, alterations are usually most pronounced on the temporal side. In a small series, Abujamra and co-workers divided the macula into four quadrants. MacTel type 2 related alterations were predominantly identified in the temporal inferior quadrant, followed by the temporal superior, and the nasal quadrants (Abujamra et al., 
2000). Such an epicenter of the disease temporal or temporal inferior to the foveal center is also suggested by microperimetry and OCT studies that assessed the localization of functional and structural alterations (Barthelmes et al., 2008a; Charbel Issa et al., 2007a).

Some patients may present with late disease manifestations in the temporal macula while the nasal side is largely unaffected. In this respect, it should be noted that progression from a sectorial to a circular involvement has not convincingly been shown longitudinally, and it might be that different subtypes are involved.

The following macular alterations may be found funduscopically in eyes with MacTel type 2 (summarized in Table 2 and Fig. 1):

- Blunting or lack of the foveolar reflex may be observed early in the disease course. Later, it is regularly absent. However, this is not uncommon in older patients, and very early disease stages may thus appear normal on funduscopy (Fig. 1A,B).

- Reduced retinal transparency ("retinal graying") in the parafoveolar area may be the first ophthalmoscopically visible change and is a hallmark of the disease (Fig. $1 \mathrm{C}-\mathrm{G})$. The graying may vanish with progressing neurosensory atrophy in later disease stages. The cause of the retinal graying is yet to be determined, however, if Müller cell dysfunction occurs early in the disease (see Chapter 14.3), then the observations may be relevant that Müller cells may act as light transmitting fibers (Franze et al., 2007) and that they are involved in retinal fluid and ion homoeostasis (Bringmann et al., 2006). Other factors that may be involved in loss of macular transparency may be structural changes within the neurosensory retina leading to increased light scatter, such as mild extracellular and/or possibly intracellular edema.

- Crystalline deposits (Fig. 1E,G,I) are located in the inner retina at the level of the inner limiting membrane (Gass and Blodi, 1993). In pronounced cases, they may be detected in OCT scans where they appear as hyperreflective dots at the anterior surface of the nerve fiber layer, arranged along the nerve fibers (Baumüller et al., 2010; Sallo et al., 2011). Crystalline deposits may be present in virtually all disease stages (Gass and Blodi, 1993; Moisseiev et al., 1990; Sallo et al., 2011). In an analysis of data derived from the MacTel study, 46\% (203 out of 443) of patients had crystalline deposits, of which $60 \%$ occurred bilaterally (Sallo et al., 2011).

- Mildly ectatic capillaries commonly become visible in stage 3 (see Chapter 8) and were described to affect mainly the deeper capillary network (Gass and Blodi, 1993). However, others identified telangiectatic vessels in both the inner and outer retinal circulation (Yannuzzi et al., 2006). Although rather commonly observed funduscopically, this alteration may be difficult to detect on fundus photographs.

- Blunted, slightly dilated venules (Fig. 1F), of which there may be one or several, are often associated with ectatic capillaries and, in later disease stages, with pigment-hyperplasia. These vessels appear not to narrow towards the foveola and suddenly seem to dive at a right angle into the deeper retinal layers. The venules might become dilated as a result of increased blood flow in the paracentral telangiectatic capillaries.

- Foveal atrophy may appear as small foveal non-prominent cysts, simulate a lamellar macular hole ("pseudo-lamellar macular hole"; Fig. 1G), or may only present with a slightly altered foveal reflectivity. Cysts and pseudo-lamellar macular holes are mostly associated with inner retinal cavities visible on OCT (see Chapter 6.2). They may be round or slightly irregular and may be slightly decentered temporally. Sometimes, two or more of these small lesions may be 
distinguished. Usually, the Watzke-Allen sign is negative and there is no accompanying epiretinal gliosis. Atrophy affecting the outer retinal photoreceptor layer appears to be the natural endpoint of the disease. There may be thinning and/ or loss of the photoreceptor layer, sometimes presenting as outer retinal cavities (see Chapter 6.2 on OCT imaging). Atrophy of the photoreceptor layer may enlarge over time and results in localized loss of function, but this development may remain rather unremarkable funduscopically. Pseudo-lamellar macular holes (only 14 out of 184 eyes in series reported by Gass and Blodi) and foveal atrophy are most likely underreported since they may easily be missed on fundus photography.

- $\quad$ Retinal pigment plaques (pigment-hyperplasia; Fig. $1 \mathrm{H}-\mathrm{J}$ ) are often associated with blunted tips of dilated venules (Gass and Blodi, 1993). They appear to originate from small foci of hyperplasia (Fig. 1G) of the retinal pigment epithelium cells that subsequently migrate into the neurosensory retina. Atrophic changes in the photoreceptor layer seem to precede and thus promote pigment-hyperplasia, which is in line with the observation that retinal pigment plaques are always associated with an absolute scotoma (see Chapter 7). Therefore, the pathophysiology may be similar to bone spicule-like pigmentation in retinitis pigmentosa: an accordant mouse model where photoreceptor atrophy with resulting direct contact between retinal vessels and the retinal pigment epithelium is associated with intraretinal pigment migration around retinal vessels (Jaissle et al., 2010). Sometimes, retinal pigment plaques may be surrounded by RPE atrophy (Fig. 1J).

- A round yellow spot (Fig. 1E), first described as a central vitelliform lesion of around 1/2-disc-diameter-size, may rarely be found centered on the fovea. Increased fundus AF and subfoveal accumulation of photoreceptor debris may be associated with such yellowish spots (see Chapters 6.2, 6.6 and 11), suggesting an accumulation of fluorophores, e.g. subretinal accumulation of photoreceptor outer segment debris or increased lipofuscin in the retinal pigment epithelium. The pseudovitelliform lesion described by others (Margalit et al., 2002) most likely refers to the same clinical finding.

- Small retinal hemorrhages may rarely occur in absence of a neovascular complex (see below) and usually resolve within several weeks.

- True lamellar or full thickness macular holes, which may present a complication during the natural disease process, have been reported in individual patients and may be confirmed by OCT imaging (Albini et al., 2006; Charbel Issa et al., 2009c; Gass and Blodi, 1993; Gass and Oyakawa, 1982; Gregori and Flynn, 2010;

Koizumi et al., 2007b; Olson and Mandava, 2006; Patel et al., 1988; Shukla, 2011; Shukla and Venkatesh, 2012). The pathogenesis may involve a progressive degeneration and atrophy of neurosensory cellular elements leading to instability of the foveal structure, possibly rendering surgery less effective than it is for other types of macular hole. Notably, macular hole formation in MacTel type 2 may show a minor temporal displacement from the foveal center. In one report, vitreoretinal surgery for two eyes with a full thickness macular hole did not result in closure of the macular hole (Charbel Issa et al., 2009c). Functional improvement was moderate in one eye (20/100-20/63) and absent in the other. There were two recent case reports on a successful closure of a full thickness macular hole in patients with MacTel type 2 (Gregori and Flynn, 2010; Shukla, 2011). However, in the second patient reported by Gregori and Flynn, the macular hole reopened after 4 months. Spontaneous closure of a small full thickness macular hole with a configuration similar to that of an idiopathic macular hole has been reported (Shukla and Venkatesh, 2012). 
- Neovascular complexes (Fig. 2) as another feature potentially complicating the natural disease course may develop at any time point. Frequently (Gass and Blodi, 1993) but not invariably (Yannuzzi et al., 2006) they are preceded by the presence of blunted venules and intraretinal pigment plaques temporal to the foveola. The lesions may present with accompanying retinal edema, yellow exudates and sub- or intraretinal hemorrhage, or may appear rather fibrotic and inactive with surrounding pigmentation and accompanying neurosensory atrophy. Neovascular complexes are most commonly located temporally to the foveola (Engelbrecht et al., 2002). The origin of these lesions appears to be different from choroidal neovascularization as observed in age-related macular degeneration. They rather seem to originate from the retinal vasculature, but may gain access to the subretinal space and may develop chorio-retinal shunts in some eyes (Davidorf et al., 2004; Engelbrecht et al., 2002; Gass and Blodi, 1993). Sometimes the membranes have the appearance of markedly ectatic capillaries, possibly representing retinal-retinal anastomosis. There might be an increased risk for developing disciform fibrotic lesions in the fellow eye if one eye is already affected (Casswell et al., 1986).

\section{Retinal imaging}

\subsection{Fluorescein angiography}

Characteristic findings on fluorescein angiography (Figs. 1, 2 and 6) are telangiectatic capillaries predominantly temporal to the foveola in the early phase and a diffuse hyperfluorescence in the late phase. The late hyperfluorescence appears to be an earlier sign than the telangiectatic alterations. Stereoscopic angiographic studies suggested that the vascular alterations mainly affect the deeper capillary plexus (Gass and Oyakawa, 1982) and that the late diffuse fluorescence on fluorescein angiography appears to originate from the outer retina. Some telangiectatic capillaries do not appear in the first dye transit as would be expected in presence of aneurysmal structural changes of the macular vasculature.

Therefore, focal staining of the vessel walls, e.g. due to an incompetent endothelial barrier, may contribute to the telangiectatic vascular appearance on fluorescein angiography. In addition to the diffuse hyperfluorescence that is due to leakage from affected capillaries, there may be mild diffuse hyperfluorescence in absence of visible ectatic capillaries in very early disease stages. This was interpreted as mild staining at the level of the outer retina (Gass and Blodi, 1993), but it may as well at least in part be due to the recently described loss of macular pigment (see Chapter 6.5) that results in a relative window defect for the choroidal background fluorescence (Gillies et al., 2009). The deep localization of diffuse hyperfluorescence observed in stereoangio-graphic studies might furthermore be explained by an effect of VEGF on the outer retinal barrier (Ablonczy and Crosson, 2007) or by the thinning or loss of outer retinal tissue resulting in apparent deep localization of vascular leakage. The hyporeflective cavities that are best visible on OCT imaging typically do not show fluoresceinpooling.

Gass and Blodi (1993) reported that in stages 1-4, the late angiographic leakage usually spares the center of the fovea, with the exception of few eyes that showed angiographic evidence of capillary ingrowth into the foveal avascular zone in the absence of neovascularisation. However, the diffuse late phase hyperfluorescence may also spread to the foveal center in absence of capillary ingrowth but with very profound leakage.

Angiographically visible paracentral alterations are usually confined to an area within one disc diameter eccentricity from the foveal center and virtually always involve the temporal sector. In 182 analyzed eyes, paracentral angiographic leakage was found to involve $90^{\circ}-$ $180^{\circ}$ in 112 eyes $(62 \%), 180^{\circ}-270^{\circ} 17$ eyes $(9 \%)$ and greater than $270^{\circ}$, i.e. all four quadrants, in 53 eyes (29\%) (Gass and Blodi, 1993). In the last case, the angiographic area of leakage generally shows a horizontal oval configuration. 
Fluorescein angiography has been the gold standard to confirm the diagnosis of MacTel type 2. However, it should be pointed out that retinal changes occur in MacTel type 2 that may be separate from the angiographically visible vascular alterations, and probably precede them. For instance, the area of increased reflectivity on confocal blue reflectance imaging (see Chapter 6.3; Fig. 6), and thus the area of macular pigment loss, is larger than the region showing late phase leakage on fluorescein angiography (Charbel Issa et al., 2008a). If the vascular alterations in MacTel type 2 represent a secondary reaction to some other primary insult, then phenotyping needs to take into account imaging modalities other than angiography.

\subsection{Optical coherence tomography}

Optical coherence tomography (OCT), a non-contact, cross-sectional in vivo imaging of the retina (Costa et al., 2006), has become a valuable tool for diagnosing and studying MacTel type 2. An overview of studies reporting findings on OCT imaging in patients with MacTel type 2 is provided in the supplementary table. There are characteristic findings on OCT imaging (overview in Table 3 ) that may present in various combinations. The changes are usually most prominent temporal to the foveal center. Larger longitudinal studies exploring the natural history on OCT imaging are currently lacking. However, based on exemplary case studies, clinical experience, and the correlation with other imaging techniques and functional parameters, a time course of alterations may be proposed (Fig. 3):

The earliest subtle changes on OCT imaging may include temporal enlargement of the foveal pit (Fig. 3B), which then appears asymmetric with its thinnest sector temporal to the anatomic foveal center (Gillies et al., 2009). This minor structural alteration appears to be due to changes in the outer nuclear/Henle's fiber layer thickness. However, if capillary leakage occurs within the same area, this asymmetric thinning may disappear due to a slight thickening mainly within the inner retinal layers (Fig. 3C). Such vascular leakage may be associated with a slightly increased reflectivity of inner neurosensory layers. Alterations of the reflectivity at the level of the photoreceptor outer segments may also be seen early in the course of the disease.

Hyporeflective cavities may develop within the inner retina (Fig. 3D-F) which are usually located in the foveal pit with a predilection for the temporal slope. These atrophic hyporeflective spaces may have the appearance on funduscopy of a lamellar macular hole ("pseudo-lamellar macular hole"; Fig. 1G). In contrast to other diseases such as diabetic maculopathy or Irvine-Gass-Syndrome, there is no angiographic leakage and pooling of fluorescein dye into the hyporeflective cavities in MacTel type 2 (Koizumi et al., 2006), and there is no similar neurosensory thickening. The hyporeflective cavities in MacTel type 2 were shown to have a reflectivity different from exudative macular cysts (Barthelmes et al., 2008b). These differences suggest that atrophy, as may be found in retinal dystrophies, rather than exudation leads to the formation of these cavities in MacTel type 2. While outer retinal cavities appear to be due to tissue loss in the photoreceptor layer (see below), inner hyporeflective cavities might also result from loss of structural integrity with a pathophysiology similar to that seen in X-linked retinoschisis or retinitis pigmentosa. As well, detachment of the foveolar neurosensory retina from the inner limiting membrane may result in a foveal hyporeflective cavity and an apparent flattening of the foveal pit, especially in presence of additional thinning of the paracentral retina (Fig. 3F). Inner hyporeflective cavities may decrease with disease progression, possibly due to loss of supporting structures, surrounding atrophy and sometimes decreasing leakage.

Another sign of the disease on OCT imaging that may occur relatively early, but which is also observed in later disease stages, is the disruption of the line commonly attributed to the photoreceptor inner segment-outer segment border. Discontinuity of this highly reflective 
line usually starts temporal to the foveola and is one of the most frequent findings in MacTel type 2 on OCT imaging. Modeling of 2-dimensional en face views at the level of the inner segment-outer segment border from densely recorded B-scans has been shown to reveal the extent of loss of this structural alteration (Sallo et al., 2012b). Two examples including enface views of the inner retina are provided in Fig. 4.

In few eyes, accumulation of subretinal debris is evident within the foveal area (Fig. 8E-F). The histopathological correlate was suggested to be degenerated photoreceptor elements that have lipofuscin-like autofluorescent properties, possibly explaining increased foveal autofluorescence and the funduscopic appearance of a yellowish foveal spot that is apparent in a small subset of eyes (Cherepanoff et al., 2012).

With disease progression, atrophy of the outer neurosensory retina, i.e. the photoreceptor layer, becomes increasingly prevalent (Fig. 3G-N). Possibly depending on the integrity of supporting structures, outer hyporeflective cavities may develop (Fig. 3G,H) and increase within the photoreceptor layer, then subsequently collapse leading to apposition of inner retinal layers onto the pigment epithelium (Fig. 3J-N). Such apposition often occurs without the intermediate stage of cavitation of the photoreceptor layer.

Hyper-reflective intraretinal lesions (Fig. 3I) are usually associated with pigment plaques. They may first appear as slightly prominent hyperreflective elevation within areas of photoreceptor atrophy, progressing into the retinal tissue. Larger lesions may present as a flat hyperreflective structure in the inner retinal layer, masking features of the underlying tissue. Secondary neovascular complexes may present as a hyperreflective lesion on OCT images (Fig. 2). In these cases the lesion typically is located in or external to the outer neurosensory retinal layers.

Quantitative analysis showed decreased thickness of the central neurosensory retina in most studies, likely due to thinning of the photoreceptor layer (Krivosic et al., 2009).

Characteristic retinal thickness maps are shown in Fig. 5 that highlight asymmetry of the foveal depression, loss of retinal contour, and a general thinning of the macular area secondary to outer retinal atrophy. It has been pointed out that apparent normal or slightly increased macular thickness may occur due to the low grade macular edema superimposed on the atrophic neurosensory retina (Charbel Issa et al., 2008d; Charbel Issa et al., 2007b). Increased macular thickness measurements may be found in MacTel type 2 eyes with marked capillary leakage and only little atrophy, in eyes with foveal detachment, pronounced pigment proliferation (Gaudric et al., 2006) or neovascular membranes.

\subsection{Confocal reflectance imaging}

Confocal reflectance imaging was suggested to be helpful in the diagnosis of MacTel type 2 as well as in the differentiation between early and late disease manifestations (Charbel Issa et al., 2008a; Charbel Issa et al., 2008b).

Imaging with a blue laser at $488 \mathrm{~nm}$ revealed an increased reflectance in the parafoveolar region of eyes with MacTel type 2 (Bottoni et al., 2010; Charbel Issa et al., 2008a; Charbel Issa et al., 2008b) (Fig. 6). This phenomenon was observed in most eyes analyzed (Charbel Issa et al., 2008a), suggesting that this non-invasive technique may be diagnostically useful. The area of increased blue reflectance is usually slightly larger than the area of hyperfluorescence in late-phase fluorescein angiography (Fig. 6), providing evidence for a disease process that goes beyond the margins of the angiographically visible vascular alterations. Interestingly, the involved area was topographically related to areas of macular pigment depletion (see Chapter 6.4) (Charbel Issa et al., 2008a). Since macular pigment has an absorption maximum near $488 \mathrm{~nm}$, its reduction would lead to decreased absorption and 
thus increased reflection of blue light. Increased light scatter due to the structural alterations of the neurosensory retina may possibly also contribute to the observed increase in reflectivity, but should not play a major role when using a confocal imaging system. There appear to be further factors that influence the appearance of confocal blue reflectance images: although loss of macular pigment and structural alterations persist, the increased reflectivity may decline in later stages of the disease. This seems to start temporal to the foveal center, possibly due to advanced neurosensory atrophic alterations, and may therefore result in a (transient) ring-shaped increased reflectance observed in some eyes.

Confocal reflectance images using an $820 \mathrm{~nm}$ laser light source may reveal decreased reflectance of the affected macular areas of eyes with progressed retinal alterations. Reduced integrity of structures with high reflectivity in the infrared range may be the cause of this decreased signal. Such structures include the inner segment-outer segment border of the photoreceptor layer which exhibits marked alterations in patients with MacTel type 2 (see Chapter 6.2). However, the ability of this technique to differentiate eyes with late from those with early disease stages has not been validated in larger studies, and other alterations affecting retinal reflectivity may be superimposed depending on the disease stage.

\subsection{Macular pigment density}

Macular pigment, consisting of lutein and zeaxanthin, is highly accumulated along the axons of the cone photoreceptors in the central retina (Davies and Morland, 2004; Snodderly et al., 1984a, 1984b; Whitehead et al., 2006). A number of functions have been proposed for macular pigment (Davies and Morland, 2004; Whitehead et al., 2006), including filtration of blue light which may reduce photic damage and glare, minimize the effects of chromatic aberration on visual acuity, improve fine detail discrimination and enhance contrast sensitivity. Its neutralization of reactive oxygen species may have a protective effect on the neurosensory retina. Although there may be a large variation with regard to the concentration of macular pigment, the pattern of distribution is relatively uniform in the normal population. It generally shows a peak concentration at the foveal center, rapidly decreasing with eccentricity and with very little at eccentricities $\geq 8^{\circ}$.

Since confocal blue reflectance imaging had suggested a focal loss of macular pigment in MacTel type 2 (Charbel Issa et al., 2008a), this was further investigated using various techniques, including two-wavelength fundus autofluorescence (AF), two-wavelength reflectance maps, spectral fundus reflectometry and heterochromatic flicker photometry (Charbel Issa et al., 2009d; Helb et al., 2008). With the exception of heterochromatic flicker photometry (representing an inadequate method in this disease because it assumes the highest macular pigment density centrally), all other analyses confirmed that macular pigment density is reduced in MacTel type 2 following a characteristic pattern. This includes a loss of macular pigment confined to or most pronounced in the area temporal to the foveal center, and no loss of macular pigment at an eccentricity of about $\succ 6.5^{\circ}$ in the horizontal axis and $25^{\circ}$ in the vertical axis (Charbel Issa et al., 2009d; Helb et al., 2008). Quantitative analysis confirmed that the loss of macular pigment was more pronounced in the temporal compared with the nasal parafoveolar area and suggested that zeaxanthin would be more reduced than lutein (Charbel Issa et al., 2009d). A trend towards a higher macular pigment density just eccentric to the central loss of macular pigment would require further analysis. Fig. 7 provides an overview on the range of macular pigment loss observed in patients with MacTel type 2.

Additional conclusive proof for the central loss of macular pigment comes from a post mortem macroscopic photograph of the eye cup from a patient suffering from MacTel Type 2 (Powner et al., 2010). Instead of the usual central yellow spot, there was a yellow ring of 
macular pigment at the same eccentricity where it would be expected from the in vivo imaging studies (Fig. 7H).

The loss of macular pigment has later been divided into 3 classes based on a cross sectional analysis of two-wavelengths fundus AF images (Zeimer et al., 2010b). Accordingly, class 1 shows a wedge-shaped loss of macular pigment restricted to an area temporal to the foveal center. In class 2 , the area enlarges and also involves the foveal center. Class 3 is characterized by loss of macular pigment within an oval shaped area centered on the foveola. There was a significant association of the consecutive 3 classes of macular pigment loss with consecutive disease stages according to Gass and Blodi. Future longitudinal studies may reveal if such classification of loss of macular pigment indeed represents consecutive disease stages or if different phenotypic sub-forms are involved.

Two patients who had lutein and zeaxanthin supplementation for several years showed higher than average macular pigment density outside the area of most pronounced macular pigment loss (Charbel Issa et al., 2009d). This suggested that accumulation of lutein and zeaxanthin may still be possible, although not in areas most affected by macular pigment depletion. In an interventional pilot study in 11 patients, Zeimer et al. further addressed the question if restoration of macular pigment density would be possible in patients with MacTel type 2 (Zeimer et al., 2010a). Oral supplementation of $12 \mathrm{mg}$ lutein and $0.6 \mathrm{mg}$ zeaxanthin for 9 months resulted in an increase of macular pigment only in areas where the macular pigment was present at baseline. Depletion of macular pigment at baseline could not be restored. It is therefore conceivable that degenerative processes in MacTel Type 2 lead to an impairment in transport and storage of lutein and zeaxanthin so that those carotenoids may simply be a marker of disease or, alternatively, may have a role themselves in the disease pathogenesis.

\subsection{Fundus autofluorescence}

Short-wavelength fundus AF using blue or green light for excitation has become in recent years a standard technique in clinical and research settings to investigate and monitor retinal disease. The short-wavelength AF signal is mainly derived from lipofuscin in the retinal pigment epithelium (Delori et al., 1995). However, it also depends on additional variables, including the presence and amount of absorbing pigments or structures.

Macular pigment (absorption maximum: $460 \mathrm{~nm}$ ) strongly absorbs blue light. Therefore, fundus AF images recorded after excitation with a $488 \mathrm{~nm}$ (blue light) laser show a strong dependency on macular pigment density and distribution. Consequently, normal eyes show a central foveal masking on $488 \mathrm{~nm}$ fundus AF images due to the central accumulation of macular pigment (Fig. 8A). Reduced macular pigment density or and/or changes in its topographic distribution in MacTel type 2 may affect this masking. Indeed, loss of the normal central attenuation of fundus AF is present in most eyes with MacTel type 2 when blue light is used for excitation (Fig. 8B,C). This effect is virtually absent when green excitation light (e.g. a $514 \mathrm{~nm}$ laser) is used because of its less significant absorbance by macular pigment.

There appear to be additional patterns of fundus AF alteration in MacTel type 2 (Fig. 8D-H) that are not explained by loss of macular pigment which, however, have not yet been studied systematically. Unbleached photoreceptor pigment has a similar, although lesser, effect on the appearance of short-wavelength fundus AF as macular pigment, as it also absorbs and therefore attenuates the excitation light available to elicit autofluorescence at the level of the pigment epithelium (Theelen et al., 2008). In the absence of retinal pigment epithelium atrophy, areas of photoreceptor atrophy (and therefore reduced photoreceptor pigment density) consequently show increased AF levels relative to surrounding areas with healthy 
photoreceptors (Fig. 8D). Bleaching of photopigment results in a shift of the spectral absorption maximum towards shorter wavelengths and therefore less absorption of blue (or green) excitation light (Theelen et al., 2008). Accordingly, photopigment bleaching decreases the difference in AF intensity between areas with and without photoreceptor loss. Hyporeflective cavities in the neurosensory retina are also associated with an increased AF signal; this may also be explained by reduced absorption of the excitation light by photoreceptors and/or macular pigment (Bottoni et al., 2010).

A further but rare alteration on fundus AF imaging in patients with MacTel type 2 is a focally increased foveal signal with a yellow foveal spot as funduscopic correlate (Fig. 8E,F; see also Chapter 5). This phenomenon is different from other fundus AF abnormalities in the sense that it is usually not decentered temporally. It neither disappears with photopigment bleaching, nor is its area correlated to loss of macular pigment. The pathophysiological correlate might be an increased accumulation of fluorophores, e.g. lipofuscin or shed photoreceptor outer segments persisting in the sub-neurosensory space (Fig. 8E, F).

A focally decreased fundus AF signal is usually due to blockage (i.e. strong absorption) of the excitation light by advanced retinal alterations, such as pigment-hypertrophy (Fig. 8H) or neovascular complexes. Furthermore, atrophy of the retinal pigment epithelium results in loss of the major fluorophores contributing to the AF signal, but this may only rarely be the cause for decreased fundus AF in MacTel type 2.

\subsection{Adaptive optics imaging}

In adaptive optics imaging, optical aberrations of the eye are reduced by compensating for distortions that are measured using wavefront analysis. Combining adaptive optics with e.g. a scanning laser ophthalmoscope allows the investigation of the photoreceptor cone mosaic in vivo (Roorda et al., 2002). Ooto et al. identified a lower paracentral cone density in patients with MacTel type 2 compared to normals using this technique (Ooto et al., 2011). There were also paracentral regions with cone loss, including areas that showed no leakage on fluorescein angiography.

\section{Functional alterations}

\subsection{Vision-related quality of life}

The vision-targeted health-related quality of life, measured with the National Eye Institute Visual Functioning Questionnaire (NEI-VFQ-25), has been analyzed in the study cohort of the MacTel Project (Clemons et al., 2008). Participants reported significantly lower visionrelated functioning in most measured subscales (except color vision) compared to a reference group with macular degeneration that had the same level of central visual acuity. Therefore, functional outcome measures different from distance visual acuity testing appear to be necessary to fully evaluate the functional deficits in MacTel type 2. This may include central visual field testing to identify characteristic paracentral scotomata (e.g. by microperimetry) or assessment of reading ability (both see below).

A similar conclusion may be drawn from a study that investigated the longitudinal impact of MacTel type 2 on vision-related quality of life using the Impact of Vision Impairment (IVI) questionnaire (Lamoureux et al., 2011). At baseline, there was a lower level of visionspecific quality of life in a subset of 22 MacTel type 2 patients compared with controls. Items associated with reading were identified as being most difficult. There was no change in distance visual acuity and no change in any of the IVI questionnaire scores at the 24 months follow up. However, other parameters of visual function were not included. Therefore, currently available quality of life studies may not fully reveal the impact of 
increasing functional defects that are characteristic and potentially sensitive for MacTel type 2 (e.g. central visual field testing, reading ability).

\subsection{Visual acuity}

Functional impairment may be mild with no or only slight reduction in binocular bestcorrected visual acuity in the early stages of MacTel type 2 . However, loss of visual acuity in at least one eye is a frequently reported complaint (Gass and Blodi, 1993). Notably, even in the presence of deep paracentral scotomata and reduced reading ability, distance visual acuity may be relatively preserved (Charbel Issa et al., 2007a; Finger et al., 2009). However, a decrease in visual acuity may eventually occur with disease progression. There appear to be essentially two different factors contributing to the decline of visual acuity (Charbel Issa et al., 2011). Initially, there may be a slow drop in visual acuity usually not below $\sim 20 / 50$ which may be due to structural foveal changes, e.g. a low-grade chronic vascular leakage or hyporeflective cavities in the inner retina. The second and more important factor for a decline in visual acuity is atrophy of the foveal photoreceptors which may result in eccentric fixation and a visual acuity of around 20/200. Such photoreceptor dropout initially occurs temporal to the foveola causing the characteristic deep paracentral scotomata (see Chapter 7.3) and may later spread centrally. If a relatively faster drop in visual acuity is observed, an associated macular hole or neovascular complex may be suspected. Visual acuity below 20/200 is rarely observed but there may be marked functional impairment in very late disease stages with large central areas of photoreceptor atrophy or due to the development of a larger neovascular complex (Engelbrecht et al., 2002; Gass and Blodi, 1993; Watzke et al., 2005; Yannuzzi et al., 2006).

Analysis of the baseline characteristics of patients enrolled in the MacTel study revealed a mean visual acuity of 20/40 in 522 untreated eyes (better eye 20/32, worse eye 20/50) (Clemons et al., 2010). Visual acuity was $20 / 20$ or better in $16 \%$, and approximately half of the eyes had 20/32 or better vision. Visual acuity was worse than 20/50 in the better eye in only $14 \%$. Characteristics for later disease stages such as pigment-hyperplasia or blunted venules were associated with a lower visual acuity (Clemons et al., 2010).

Similar results were found in the cohort reported by Gass and Blodi (1993): visual acuity was $20 / 20$ or better in $32(18 \%)$ of 182 eyes and median visual acuity was 20/40 (range $20 / 15$ to hand motions). No patient had a visual acuity of 20/200 or worse in both eyes (Gass and Blodi, 1993). They stated that most patients would become symptomatic only after occurrence of stage 3 changes (see Chapter 8 ) and some maintained good visual acuity even after stage 4 changes had developed. Of their 92 patients, 72 were followed for at least 2 years with a mean follow up time of 91 months (range 24-316 months). The final visual acuity was $20 / 30$ or better in at least one eye of 27 patients. In the 37 eyes with 20/200 or less visual acuity, the primary cause was foveal atrophy in 26 eyes, neovascular complex 10 eyes, and cataract in 1 eye. Ten patients were legally blind at the last follow-up.

Watzke and co-workers reported that visual acuity may decline gradually but, overall, $25 \%$ of eyes (6 out of 24) remained stable during a review period of 10-17 years (Watzke et al., 2005). Engelbrecht et al. retrospectively studied the natural visual outcome in 26 eyes that developed stage 5 disease (Engelbrecht et al., 2002); 80\% of these eyes had a final visual acuity of 20/100 or worse.

\subsection{Central visual field}

Metamorphopsia or a positive scotoma in patients with MacTel type 2 was noted in earlier case series (Abujamra et al., 2000; Gass and Oyakawa, 1982). To explore further the presence of scotomata, we used fundus-controlled perimetry (microperimetry) to record 
functional deficits with high resolution (Charbel Issa et al., 2007a) (Fig. 9). Early disease stages (stages 1 and 2; see Chapter 8) usually showed preserved retinal sensitivity. In later stages, paracentral sensitivity declined showing the main defects at about $2^{\circ}$ eccentricity temporal and temporal inferior to the foveal center. Depending on the presence and extent of photoreceptor atrophy, such deep scotomata may or may not be present in stage 3. In stages 4 and 5 , absolute scotomata can almost always be detected, usually topographically related to retinal pigment hyperplasia or neovascularisation on funduscopy which both are associated with atrophy of the photoreceptor layer on OCT imaging (Charbel Issa et al., 2007a). Although it may initially be difficult to detect the small and localized scotomata, they may enlarge due to progressive photoreceptor atrophy. This may eventually lead to a central scotoma involving the foveal center and paracentral areas possibly as large as the angiographically visible affected area. Detection of the paracentral scotomata revealed by microperimetry was poor using the Amsler grid (Charbel Issa et al., 2009b). This is likely due to perceptual completion of small functional defects, which consists of a fillingin of the missing information when part of an image falls on a blind area of the visual field (Gerrits and Timmerman, 1969).

Visual acuity was correlated with the central foveal light sensitivity but not with the paracentral light sensitivity temporally (Charbel Issa et al., 2007a), suggesting that microperimetry would indeed add information on the functional alterations in MacTel type 2. This assumption was supported by a recent analysis of longitudinal data from an interventional study that showed no change in visual acuity but a decrease in paracentral light sensitivity on microperimetry (Charbel Issa et al., 2010).

Fine matrix mapping to study the scotopic function within the central visual field revealed an earlier decrease and more severe affection of scotopic rod compared to photopic cone function (Schmitz-Valckenberg et al., 2008). A subsequent longitudinal observation of nine eyes over one year suggested a superior sensitivity of scotopic fine matrix mapping to monitor progression of the functional deficit compared with microperimetry (SchmitzValckenberg et al., 2009). Assessment of scotopic macular function using fine matrix mapping is, however, time consuming and not widely available. Therefore, it may not be suitable for larger patient cohorts in clinical trials.

Patients typically do not complain of peripheral visual field defects, and perimetry of the retinal periphery has not been systematically performed.

\subsection{Reading ability}

Efficient reading requires not only sufficient visual acuity to resolve the letters, but also a sufficient extent of central visual field of usually at least $4^{\circ}$ to sufficiently process words and to perform adequate eye movements (Trauzettel-Klosinski, 2002). It was therefore hypothesized that the characteristic paracentral scotomata could impair the reading ability of patients with MacTel type 2 . Indeed, these patients exhibit a significantly reduced monocular reading acuity (mean 20/63) and considerably reduced reading speed to almost 50 words per minute compared with an average of 190 words per minute in the control group (Finger et al., 2009). Regression analysis showed that a reduction in distance visual acuity and the characteristic temporal scotomata were significant predictors for both variables of reading performance (reading speed and reading acuity). The fixation stability was not significantly different from controls (Finger et al., 2009). Accordingly, these findings indicated that paracentral sensitivity loss in MacTel type 2 is associated with loss of reading performance despite stable central fixation. Since it has been shown in several studies of other retinal diseases that reading ability is strongly associated with quality of life, therapeutic intervention in MacTel type 2 should be aimed at maintaining patients' reading ability (Finger et al., 2009). 


\subsection{Metamorphopsia}

Metamorphopsia has been rarely investigated in retinal diseases in a systematic way, most likely due to the scarcity of standardized and validated tests that would allow its quantification. We showed that in the majority $(83 \%, n=36)$ of eyes without neovascularization perception of distortions could be detected with the Amsler grid (Charbel Issa et al., 2009b). If present, metamorphopsia was always detected in the nasal quadrant of the central visual field, and were strongest in the nasal and upper quadrant of the testing grid. This localization of metamorphopsia is consistent with the predominant disease manifestation temporal/temporal inferior to the foveal center. The degree of distortions often but not always correlated with the degree of angiographically visible leakage.

Metamorphopsia was also present in eyes with earlier disease that showed no scotoma on microperimetry testing and thus appears to be an early symptom in MacTel type 2. A quantitative analysis of metamorphopsia, e.g. using m-charts (Matsumoto et al., 2003), as well as correlations with other vision related tasks has not yet been performed.

\subsection{Electrophysiology}

Gass and Oyakawa reported the first electrophysiologic studies in three patients with MacTel type 2 (Gass and Oyakawa, 1982). Electrooculography and full-field electroretinography were found to be normal. However, a recent case report presented a patient with features of cone dystrophy with significantly reduced cone-driven responses on electroretinography (Barthelmes et al., 2007). Three years later, the patient had developed features typical for MacTel type 2 including vascular alterations on fluorescein angiography. Larger studies including multifocal electroretinography will be necessary to further elucidate electrophysiologically measurable deficits in MacTel type 2.

\section{Structure-function correlation}

Since microperimetry seems to be most appropriate for measuring functional deficits in patients with MacTel type 2, several studies have been reported on the structure-function correlation based on microperimetry data (Charbel Issa et al., 2008d; Charbel Issa et al., 2007a; Charbel Issa et al., 2010; Maruko et al., 2008; Schmitz-Valckenberg et al., 2008, 2009; Wong et al., 2009). If no marked atrophic alterations are present, there appears to be no correlation between retinal thickness and retinal sensitivity (Charbel Issa et al., 2008d). Thus, it was concluded that qualitative assessment of the retinal structure would be more meaningful than retinal thickness analysis. Such cross sectional qualitative analysis revealed that marked defects in retinal sensitivity are correlated with outer retinal atrophy on OCT imaging and with pigment-hypertrophy on fundus photography (Charbel Issa et al., 2007a; Maruko et al., 2008; Schmitz-Valckenberg et al., 2008; Wong et al., 2009). However, those studies showed no point-to-point correlation and included only small patient numbers. A subsequent high-resolution structure-function correlation confirmed the importance of outer retinal alterations for functional loss. While structural damage to the outer retina (photoreceptor layers) was accompanied by a loss of retinal sensitivity as detected by microperimetry, structural changes limited to the inner retina typically showed preserved function (Charbel Issa et al., 2010). The same study revealed that there appears to be an association of retinal function with the photoreceptor layer thickness (Charbel Issa et al., 2010). Conclusions on retinal function based on total retinal thickness measurements may be less valid due to low grade retinal edema, pigment migration or neovascular complexes that all may add to this thickness parameter (Charbel Issa et al., 2008d). Microperimetry data was also overlaid with en face OCT-images at the level of the inner segment-outer segment border. This study revealed an association between discontinuity within this OCT-feature and reduced retinal sensitivity (Sallo et al., 2012b). Zeimer et al. investigated the possible correlation of macular pigment loss with microperimetry data (Zeimer et al., 2010b) and 
found a trend towards worse retinal function with increasing class of macular pigment changes (see Chapter 6.4). Correlations with disease characteristics on fundus AF imaging (Wong et al., 2009) should be considered carefully due to the variable functional impact of the different fundus AF phenomena (see Chapter 6.6).

Distance visual acuity has been correlated with structural alterations from baseline data of the MacTel Natural History study cohort (Clemons et al., 2010). The presence of pigmenthypertrophy as well as of blunted venules showed the most significant association with decreased visual acuity. Characteristic fundus AF patterns, especially when involving the foveal center, as well as disease specific (but not further divided) OCT characteristics also revealed a significant association with visual acuity. Gaudric et al. (2006) pointed out that the frequently observed disruption of the photoreceptor inner segment-outer segment border (see Chapter 6.2) does not necessarily mean photoreceptor loss, since function may still be retained. The authors suggested that the signal of this highly reflective line might be impaired by a change in the spatial orientation of the photoreceptor outer segments or by any other change in their structure. Accordant, foveal center involvement of the area with loss of the inner segment-outer segment border showed no significant correlation with visual acuity (Sallo et al., 2012b). Ooto et al. found a correlation of cone density with the integrity of the border between inner and outer photoreceptor segments and with visual acuity using adaptive optics (Ooto et al., 2011). As mentioned in Chapter 7.2, photoreceptor atrophy of the foveal center might be the most important factor determining distance visual acuity; however, this has not yet been investigated in detail. The pattern of macular pigment loss appears to have some correlation with distance visual acuity (Zeimer et al., 2010b). There was significantly better visual acuity in eyes with macular pigment alterations consistent with class 1 compared with those with a loss of central macular pigment density (class 2 and 3; see Chapter 6.4).

Overall, it appears that spectral domain OCT studies with a dense B-scan raster may be a promising surrogate for assessment of disease progression in MacTel type 2 (Charbel Issa et al., 2010). This may be achieved either by analyzing B-scans individually (Charbel Issa et al., 2010) or by using those data to construct en face views at defined retinal layers (Sallo et al., 2012b). However, strong evidence still needs to be provided for such surrogate markers. For disease staging and measurement or prediction of progression, other parameters, including macular pigment distribution, funduscopic findings or angiographic disease activity, may also need to be considered.

\section{Disease staging}

There appears to be a chronological appearance of the various fundus changes. Of note, subtle macular alterations may be detected on clinical fundus exam but may be missed on fundus photographs analyzed in studies, leading to a possible underestimation of the true frequency of certain findings (Table 2). Generally, the first visible alterations appear at the foveola (changes of foveolar reflex, pseudo-lamellar macular hole) and temporal to the foveola (retinal graying). The disease may later spread to encompass the entire oval macular area with the most pronounced alterations temporally (Davidorf et al., 2004). With progressing photoreceptor atrophy, ectatic capillaries and retinal graying may disappear, and this again usually first occurs in the temporal parafoveolar quadrants. In a subset of patients, the asymmetry within one eye may be very pronounced, so that nasal paracentral macular areas may appear normal while marked atrophy is present temporal to the foveola.

Gass and Blodi suggested a temporal sequence of 5 disease stages (Table 1) based on a retrospective analysis of fundus photography and fluorescein angiographic findings (Gass and Blodi, 1993), without the currently available technology, including fundus 
autofluorescence, optical coherence tomography (OCT) and microperimetry. According to their system, stage 1 is characterized by only mild hyperfluorescence on angiography, usually temporal to the foveola. In stage 2, there is a slight graying of the parafoveolar retina and minimal or no visible telangiectatic vessels. Stage 3 is characterized by dilated right angled vessels that may be both venular and arteriolar in nature and stage 4 by intraretinal proliferation of pigment epithelial cells typically along right angled vessels. Stage 5 is characterized by secondary neovascularization. Longitudinal observations of serial photographs (64 eyes of 32 patients, follow up of 2 years or longer) revealed the development of new pigment plaques in 20 eyes, a new neovascular complex in 7 eyes, new superficial crystalline deposits in 5 eyes, the appearance of right-angled venules in 5 eyes and of focal atrophy simulating a lamellar macular hole in 3 eyes (Gass and Blodi, 1993).

Using the classification as suggested by Gass and Blodi, a low inter-observer reliability for stages 1-3 was reported (Charbel Issa et al., 2007a). A deep and circumscribed paracentral scotoma, the characteristic functional loss in MacTel type 2 (see Chapter 6.2), is always found in stage 4 but may or may not be present in stage 3, depending on atrophic alterations in the photoreceptor layer (Charbel Issa et al., 2007a). Neovascular complexes do not strictly occur in the proposed disease sequence, i.e. as the last stage of the disease. Similar to macular holes, which may develop due to a disease-related decreased stability of the foveal structure, development of neovascular complexes may occur at any time during the course of the disease. Thus, a suggested classification that divides the condition into nonproliferative and proliferative (i.e. eyes with neovascular membranes) stages (Yannuzzi et al., 2006) may be misleading. The natural endpoint of the disease, localized atrophy of the photoreceptor layer, is not considered in this classification.

In conclusion, the disease staging according to Gass and Blodi still appears to be the best staging system, with a chronological sequence of the biomicroscopically visible features essentially in line with clinical experience. However, their staging does not take into account the recent advances revealed by novel imaging techniques. Longitudinal data including disease characteristics that have only become apparent with the advent of new technology, such as the development of paracentral scotomata caused by focal photoreceptor death and the loss of macular pigment, need to be taken into account to develop a more accurate description of disease staging and progression.

\section{Additional associated ocular findings and systemic diseases}

Based on an analysis in 55 patients and 170 controls, a generally wider arteriolar and venular calibre outside the macular area was reported in patients with MacTel type 2 (Tikellis et al., 2009). The authors suggested that such generalized changes in retinal vascular calibre might reflect an underlying dysfunction of retinal pericytes or glial cells, and might provide a means to monitor progression of disease. An alternative possible explanation would be that the vascular calibre widens due to an increased blood flow within the macular area.

A smaller foveal avascular zone compared to normal has been reported in patient with idiopathic juxtafoveolar telangiectasia (Mansour and Schachat, 1993); however, the proportion of patients with MacTel type 2 in this study remains unclear and it appears that mainly other disease entities had been analyzed. Another study described two cases with a centripetal retinal capillary proliferation (Koizumi et al., 2007a). From clinical experience, synchisis scinitllans and small hard drusen with an associated window defect on fluorescein angiography (similar to basal laminar drusen) might be more common in MacTel type 2 patients. Both possible associations have been reported (Charbel Issa et al., 2007c; Margalit et al., 2002), but have not been validated in a larger patient group. Co-occurrence of such 
ocular findings may be part of the phenotype of MacTel type 2 or may have been found due to co-existence by chance, depending of the strength of association that would need to be assessed in larger patient cohorts. So far, no data is available regarding refraction or lens status. Notably, an increase of vascular leakage was observed after cataract surgery (Toy et al., 2012), pointing to a possible effect of confounding factors on disease activity.

With regards to potential associations with systemic diseases, baseline analysis of the MacTel study cohort revealed a high prevalence of a history of diabetes mellitus (28\%) and hypertension (52\%). $41 \%$ were overweight (body mass index 225 ) and $43 \%$ were obese (body mass index 230 ). $12 \%$ were current and 38\% former smokers (Clemons et al., 2010). However, there may be sampling (ascertainment) bias. Also, diabetes mellitus and hypertension could lead to increased vulnerability of the macular vasculature for the eponymous vascular alterations. It had been proposed already in earlier studies that diabetes mellitus may be associated with the disease (Chew et al., 1986; Millay et al., 1986). However, others suggested that the association would not be stronger than expected in an age matched population (Maberley et al., 1999; Yannuzzi et al., 2006). In the study by Gass and Blodi, only one patient had borderline diabetes and six patients (8\%) developed diabetes within a mean follow up period of 91 months (Gass and Blodi, 1993).

Many other ocular (Bakke and Drolsum, 2006; Gass and Oyakawa, 1982; Querques et al., 2010) and systemic (Abujamra et al., 2000; Fitzsimons et al., 1987; Gass and Blodi, 1993; Gurwin et al., 1985; Lee et al., 2004; Leys et al., 2000; Parodi et al., 2006; Yannuzzi et al., 2006) associated diseases have been reported. However, these often were only single observations and certainly could represent the normal prevalence in the population and thus coincidence.

\section{Histology}

Green et al. published a light and electron microscopic study of an eye with confirmed MacTel type 2 (Green et al., 1980). Notably, they did not find telangiectatic vessels within the macular area. They reported narrowing of the capillary lumen from proliferation of a multilaminated endothelial cell basement membrane, a partial loss of pericytes, accumulation of lipids within the capillary walls and localized areas with disrupted endothelial cells. The neurosensory retina showed intracellular and intercellular edema in the temporal paracentral area with granular material in the extracellular spaces. Some ganglion cells and cells in the inner nuclear layer appeared to be undergoing degeneration. The outer nuclear layer was less affected and the retinal pigment epithelium appeared normal. They postulated that the angiographic appearance of telangiectasis could be due to rapid diffusion of the dye into the thickened wall of the capillary sites of endothelial cell degeneration, subsequent diffusion within the wall and eventual leakage into the surrounding tissue. It should be noted that data on the normal appearance of the aged human retinal vasculature on electron microscopy is scarce. Green et al. did not contrast their findings to an age matched control and moreover found similar changes as described for the macular area in the retinal periphery. Notably, Powner et al. have recently identified similar alterations in normal eyes from donors of similar age as the patient reported by Green et al., further suggesting that caution should be exercised in the interpretation of histopathological case studies without controls (Powner et al., 2011).

In a separate study, Powner et al. used immunohistological techniques to assess a donor eye with a well documented diagnosis of MacTel type 2. An angiogram 12 years before the patient's death showed alterations characteristic for MacTel type 2. Striking loss of central macular pigment was evident macroscopically (see Chapter 6.5). Histology revealed abnormally dilated vessels in the deeper plexus of the retinal paracentral vasculature. 
Immunohistochemistry suggested a marked reduction of basement membrane proteins indicating vascular pathology. Claudin-5, a marker for tight junctions between retinal endothelial cells, showed immunoreactivity in normal as well as in telangiectatic vessels. Most notable was a lack of reactivity to Müller cell markers (including vimentin and glutamine synthetase) within the area of macular pigment loss, most likely due to loss or disease of Müller cells. Due to poor preservation of the photoreceptors in the available sections, no definite conclusions were possible regarding the extent of photoreceptor loss. No differences compared with a control eye were observed on the immunohistological staining for macrophages using the Iba1 microglia marker and no obvious abnormalities were found within the retinal pigment epithelium (Powner et al., 2011). The Müller cell pathology observed in this histological specimen was confirmed by a proteomic study of the fellow eye. It revealed a reduction of proteins involved in the glycolytic pathway which occurs in Müller cells, and of glial cell markers in the diseased macula (Len et al., 2012). The fellow eye was also studied by electron microscopy (Cherepanoff et al., 2012). The most significant finding was a subretinal accumulation of degenerate photoreceptor elements within the central retina with only minimal retinal pigment epithelial reaction and a normal appearing Bruch's membrane. There was also a focal loss of the outer limiting membrane and mild irregularity of the inner limiting membrane within the central retina.

Davidorf et al. (2004) presented the histopathological findings of a surgically excised neovascular complex in a patient with MacTel type 2. Notably, the vascular membrane originated from the retinal vessels and no connection to the underlying choriocapillaris was found.

A further histopathological study of presumed parafoveal telangiectasis is mentioned for completeness (Eliassi-Rad and Green, 1999). The authors described histological findings that appear not to be compatible with the current concept of MacTel type 2. There was no clear clinical diagnosis of MacTel type 2 made before the patient's death, suggesting a different diagnosis.

\section{Differential diagnosis}

Several features of MacTel type 2 may be found in other diseases that should be considered when funduscopic assessment allows no clear-cut diagnosis. Findings that may be helpful in distinguishing MacTel type 2 include the temporal predilection of a bilateral disease process not respecting the horizontal raphe, the characteristic inner and outer retinal cavities seen on OCT imaging and the loss of macular pigment visible on fundus AF imaging. Further clues may be the apparent lack of retinal thickening despite vascular (low grade) leakage due to underlying retinal atrophy, and more pronounced visual disturbance (e.g. reading difficulties) than expected from distance visual acuity testing, which is due to characteristic paracentral absolute scotomata in progressed disease stages.

\subsection{Macular telangiectasia type 1}

MacTel type 1 (see Table 1), also termed "aneurysmal telangiectasia", mainly occurs unilaterally, affecting predominantly young males (Abujamra et al., 2000; Casswell et al., 1986; Gass and Blodi, 1993; Gass and Oyakawa, 1982; Lowe et al., 1998; Millay et al., 1986; Watzke et al., 2005; Yannuzzi et al., 2006). It is less prevalent than MacTel type 2, although this might not be true in all populations (Lee et al., 2011; Maruko et al., 2012). Little is known of its pathophysiology and natural history. It may be that the classification into type $1 \mathrm{~A}$ and $1 \mathrm{~B}$ represents different stages of the same disease rather than different disease groups (Gass and Blodi, 1993; Watzke et al., 2005; Yannuzzi et al., 2006). It has been proposed that the disease is a developmental disorder which represents a mild variant of Coats' syndrome and Leber's miliary aneurysms (Cahill et al., 2001; Gass and Blodi, 
1993). Disease severity may be associated with age of onset, with earlier disease occurrence having the worse prognosis (Cahill et al., 2001). No clear association with systemic or other ocular diseases has been identified.

The characteristic funduscopic findings of MacTel Type 1 include visible aneurysmatic dilation of the macular blood vessels, mainly confined to the temporal region, with surrounding cystoid macular edema and yellowish exudates (Gass and Blodi, 1993; Yannuzzi et al., 2006). The presence of microaneurysms is an important feature to distinguish MacTel Type 1 against MacTel Type 2, where microaneurysms are not a characteristic phenotypic feature. Also, MacTel Type 1 is a unilateral disease, whereas MacTel Type 2 is bilateral. A serous or exudative detachment of the macula, a cicatricial disciform macular lesion and haemorrhages may develop (Yannuzzi et al., 2006). The vascular changes typically involve an irregular or oval zone and are centered temporal to the fovea. Vascular alterations in extramacular areas were reported to occur in 20\%-50\% (Casswell et al., 1986; Gass and Blodi, 1993; Gass and Oyakawa, 1982; Yannuzzi et al., 2006) or were not observed (Abujamra et al., 2000; Lowe et al., 1998). The different proportions of peripheral involvement may be due to different definitions of peripheral or extramacular location, the restricted availability of peripheral angiographic images in retrospective case series or different diagnostic criteria in the respective studies.

Fluorescein angiography typically reveals vascular aneurysmal widening of the macular vessels in the early phase with diffuse leak and cystoid edema in the late phase (Gass and Blodi, 1993; Yannuzzi et al., 2006). There may be variable capillary occlusion or loss, possibly secondary to longstanding neurosensory edema (Gass and Blodi, 1993; Yannuzzi et al., 2006). On indocyanine green angiography, there commonly is staining of the aneurysmal vascular changes in the late angiographic phase, which is usually not observed in MacTel type 2. Optical coherence tomography (OCT) shows cystoid macular edema with retinal thickening (Surguch et al., 2006; Yannuzzi et al., 2006), a localized neurosensory detachment may be present (Yannuzzi et al., 2006). The characteristic localized loss of macular pigment within the central retina as described for MacTel type 2 is not present in type 1 ; however, central macular pigment density has been noted to be slightly decreased compared to normal (Sawa et al., 2012).

Complaints reported by patients with MacTel type 1 include impaired visual acuity and blurred vision, less frequently metamorphopsia or a negative scotoma (Abujamra et al., 2000; Gass and Oyakawa, 1982). Patients with MacTel type 1 may present with advanced disease since they usually have one unaffected eye. Progressive visual impairment is usually associated with an increase in the extent of telangiectasia, prominent cystoid macular edema and/or lipid exudates extending into the foveal center. In a recent structure-function correlation, disruption of the inner segment-outer segment border and cystoid retinal thickening was found to be associated with reduced retinal function (Takayama et al., 2012). Patients with type 1B disease usually only report mild metamorphopsia while visual acuity may be preserved.

Focal laser photocoagulation (direct coagulation of aneurysms) has been reported to decrease vascular exudation and may improve visual acuity in some patients (Chopdar, 1978; Gass, 1968; Gass and Blodi, 1993; Gass and Oyakawa, 1982; Lowe et al., 1998; Millay et al., 1986). The success of treatment may depend upon the extent of pre-existing neurosensory damage due to longstanding edema or lipid exudates extending into the foveola. Repeated treatment may be necessary.

Single reports showed that intravitreal administration of the steroid triamcinolone may result in a decrease of the macular edema associated with MacTel type 1 (Charbel Issa et al., 
2007c; Li et al., 2005). Intravitreal injections of the VEGF-inhibitor bevacizumab have also been tried, but these resulted in reduction of retinal edema and an increase in visual acuity in only few eyes (Gamulescu et al., 2008; Matsumoto and Yuzawa, 2010; Takayama et al., 2010). The vascular alterations, which likely are structural in nature, did not disappear completely with either intravitreal steroids or VEGF-inhibitors, the effect in most cases being only temporary with recurrence of macular edema after cessation of therapy.

Information from controlled prospective trials to address systematically the natural history and potential long-term treatment effects in this rare condition is lacking. Rebound phenomena following therapy were described after different treatment approaches and changes of the activity of the disease, including spontaneous stabilization and even resolution of the macular edema without treatment have been reported (Gass and Blodi, 1993; Gass and Oyakawa, 1982). Therefore, intervention should be recommended thoughtfully and weighed against potential risks and side effects. If central vision is in danger due to threatened extension of lipid exudates into the foveola, intervention should seriously be considered.

\subsection{Other diseases associated with macular telangiectasia}

Telangiectatic vascular alterations within the macular area may be observed in diabetic retinopathy, radiation retinopathy, branch retinal vein occlusion or secondary to inflammatory ocular disease. A thorough medical history is essential. Except in small branch retinal vein occlusions, these diseases usually reveal more wide-spread and additional fundus changes, including alterations such as haemorrhages and nerve fiber layer infarcts. Exudative cystoid macular edema commonly accompanies retinal vascular disease. Branch retinal vein occlusions usually respect the horizontal raphe and occur distal to an arteriolarvenular crossing. If the vascular alterations occur secondary to an inflammatory disease, further related findings such as vitreous cells and/or vascular sheathing may be present. Little is known about rare types of idiopathic macular telangiectasia as proposed in Gass and Blodi's type 3, which are associated with capillary occlusion and systemic diseases (Gass and Blodi, 1993). Rare syndromic occurrence of macular telangiectasia may also include patients with dyskeratosis congenita (Yannuzzi, 2010) or facioscapulohumeral muscular dystrophy (Fitzsimons et al., 1987; Gurwin et al., 1985).

\subsection{Diseases with similar neurosensory atrophy}

Hyporeflective cavities of the neurosensory retina observed with OCT imaging similar to those in MacTel type 2 have been reported in patients with a variety of inherited retinal dystrophies (Barthelmes et al., 2008b; Kellner and Kellner, 2009; Mahajan et al., 2009). Also, the area affected in MacTel type 2 is similar to that involved in various inherited dystrophies that present with e.g. bull's eye maculopathy (Kurz-Levin et al., 2002; Michaelides et al., 2007).

Atrophic alterations on OCT imaging as observed in MacTel type 2 have also been reported in patients with Tamoxifen-Retinopathy and with Sjögren-Larsson-Syndrome, including hyporeflective cavities in the photoreceptor layer and retinal thinning (Fuijkschot et al., 2008; Gualino et al., 2005; Mauget-Faysse et al., 2006). However, no similar vascular changes have been shown in the few available angiographic reports of these conditions (Gualino et al., 2005; Willemsen et al., 2000). Notably, funduscopy in such patients may reveal crystalline deposits as in MacTel type 2 (Drenser et al., 2006). Moreover, patients with Sjögren-Larsson-Syndrome showed a complete lack of macular pigment (van der Veen et al., 2010) suggesting a similar pathophysiological process as in the localized areas of macular pigment loss in patients with MacTel type 2 (see Chapter 6.5). The medical history 
or, in patients with Sjögren-Larsson-Syndrome, concomitant syndromic symptoms, are usually helpful for the differential diagnosis.

\subsection{Miscellaneous other diseases}

In age-related macular degeneration, drusen are usually present early in the disease course. Late disease stages are characterized by the either geographic atrophy or neovascular membranes originating from the choroidal vasculature (in contrast to the primarily retinal origin of neovascular complexes in MacTel type 2).

Further macular alterations that may be considered in the differential diagnosis of selected cases are Irvine-Gass syndrome in pseudophakic patients, solar retinopathy which may present with a yellowish foveal lesion on funduscopy and atrophic changes within the foveal photoreceptor layer on OCT imaging, other diseases with crystalline retinal deposits (Drenser et al., 2006) including West African crystalline maculopathy that may show similar crystalline deposits in the inner retina (Sarraf et al., 2003), macular full thickness and lamellar holes, or epiretinal gliosis.

\section{Treatment}

Various approaches have been investigated to treat MacTel type 2 (Table 4). Most available reports are single cases or retrospective small case series, with no data available from larger controlled prospective trials.

The slow progression of functional defects in MacTel type 2 (Fig. 9) makes it difficult to measure treatment effects particularly over short periods of time. Outcome parameters different from visual acuity assessment, such as microperimetry or enlargement of areas of photoreceptor loss on OCT appear more suitable for monitoring treatment effects in MacTel type 2 (see Chapters 8 and 9). Only few publications with small patient numbers have reported such parameters. Moreover, short term effects such as improvement in visual acuity after intravitreal application of bevacizumab (see below) may be due to the temporary decrease of neurosensory edema without affecting the natural history of the disease course, i.e. the slowly progressive photoreceptor atrophy. Therefore, due to insufficient information, general recommendations concerning the treatment of MacTel type 2 cannot currently be made.

Since the potential gain of function after any treatment might be limited by pre-existing neurosensory atrophy, initial thorough phenotypic and functional characterization is most important. The timing of intervention may be crucial since any treatment might be ineffective once neurosensory atrophy or fibrosis have occurred.

This chapter is divided into treatment approaches for nonproliferative and proliferative phases. A separate paragraph in Chapter 5 summarizes reports of treating macular holes in eyes with MacTel type 2 .

\subsection{Nonproliferative stage}

Despite individual observations of improvement after focal argon laser photocoagulation for MacTel type 2 (Chopdar, 1978; Hutton et al., 1978), most of the literature suggests no beneficial effect (Gass and Blodi, 1993; Kiraly and Nasemann, 1995; Lowe et al., 1998; Park et al., 1997). Park and co-workers retrospectively analyzed the long-term outcome (median follow up time: 73 months) in 10 eyes of 8 patients. Visual acuity did not change significantly and a reduction of macular edema was only achieved in $20 \%$ of treatments. Compared with untreated eyes, previous laser photocoagulation was associated with distortion of retinal vessels, more fibrovascular tissue, retinal pigment epithelial clumping, 
new draining venules and retinal hemorrhages. Argon laser photocoagulation for MacTel type 2 may be complicated by subretinal hemorrhage (Friedman et al., 1993) and induction of new fibrovascular membranes (Engelbrecht et al., 2002; Gass and Blodi, 1993; Park et al., 1996; Watzke et al., 2005). Therefore, because no proven benefit has been shown and because there may be an increased risk for developing neovascular complexes, laser photocoagulation is not recommended for the treatment of non-proliferative MacTel type 2.

Photodynamic therapy was used in two eyes of two patients with non-proliferative MacTel type 2 (De Lahitte et al., 2004). In neither patient did the authors observe significant changes in visual acuity, fluorescein angiographic leakage or OCT findings.

Intravitreal injection of triamcinolone (IVT) has been reported to reduce late phase hyperfluorescence in fluorescein angiography with (Martinez, 2003) or without (Alldredge and Garretson, 2003; Cakir et al., 2006) an improvement of more than two lines in visual acuity. Smithen and Spaide did not find an effect on either fluorescein angiography or visual acuity (Smithen and Spaide, 2004). There appeared to be a reduction in retinal thickness after IVT followed by a waning of the effect after nine months in one report (Cakir et al., 2006). In the largest study reported to date, the change in visual acuity of 19 eyes (14 patients) which received one or two IVT injections was analyzed retrospectively (Wu et al., 2008). After a mean follow-up of 21.2 months (range, 6-44 months), there was a gain and loss of $\geq 3$ lines in 4 eyes each, and a stable visual acuity in the remaining 11 eyes. IVT had a beneficial anatomical and functional effect in a MacTel type 2 patient presenting with bilateral foveal detachment (Maguluri et al., 2007).

Posterior juxtascleral administration of anecortave acetate, an angiostatic synthetic cortisol derivative supposedly without corticosteroid bioactivity, was reported to stabilize visual acuity over 24 months in two non-proliferative eyes. However, no data were provided with regard to the natural history in the fellow eye for comparison, the angiographic effects, or alterations on OCT-imaging (Eandi et al., 2006).

Short term observation after inhibition of VEGF using intravitreal bevacizumab, resulted in a marked decrease of parafoveolar leakage, normalization of macular capillaries and decrease in retinal thickness. Visual acuity was reported to improve in few patients (Charbel Issa et al., 2007b; Charbel Issa et al., 2007d; Toy et al., 2012). Other studies have not found similar effects, possibly because treated eyes had more advanced disease (Charbel Issa et al., 2009a; Gamulescu et al., 2008; Kovach and Rosenfeld, 2009). As a result of the chronic nature of the disease, the effect of the anti-VEGF-treatment tended to wear off after two to four months (Charbel Issa et al., 2008c; Toy et al., 2012). Further studies with longer follow up identified a beneficial effect of intravitreally applied bevacizumab in patients who were treated on a pro re nata (PRN) regimen over a mean follow up time of 18 (Charbel Issa et al., 2008c) or 32 (Matt et al., 2010) months. Conclusions from those studied are limited due to the small patient cohorts and the retrospective study design. In two prospective studies on anti-VEGF treatment for MacTel type 2, patients were treated monthly with ranibizumab for one year (Charbel Issa et al., 2011; Toy et al., 2012). At the end of those studies, there was no effect on visual acuity. While the overall light sensitivity within the area of vascular leakage might increase slightly (Toy et al., 2012), paracentral photoreceptor atrophy and corresponding scotomata had progressed slowly despite a clear effect on the vascular alterations (Charbel Issa et al., 2011; Charbel Issa et al., 2010). It was concluded that monthly ranibizumab is not recommended for patients with MacTel type 2. In view of the neuroprotective properties of VEGF (Nishijima et al., 2007; Saint-Geniez et al., 2008), its constant inhibition could potentially be harmful when treating a neurodegenerative disease such as MacTel type 2 in the long term. 
A potential benefit of short-term intravitreal VEGF inhibition on foveal detachment in MacTel type 2 has been reported (Lira et al., 2010; Maia Junior et al., 2007; Windisch and Kozousek, 2008). The foveal anatomy regained its normal configuration with improved visual acuity in several retrospectively analyzed cases. This observation needs further investigation in larger prospectively designed trials.

A recent retrospective case series compared observation $(n=33)$ with intravitreal bevacizumab $(n=15)$ or pars plana vitrectomy $(n=8)$ for non-proliferative MacTel type 2 (Sigler et al., 2012). The authors found no difference in change of visual acuity within a mean follow-up period of $24 \pm 13$ months.

\subsection{Proliferative stage}

Various treatments have been used for subretinal neovascularisation, which is a major cause of severe vision loss in a minority of patients with MacTel type 2 (Engelbrecht et al., 2002; Gass and Blodi, 1993; Yannuzzi et al., 2006). Park and co-workers found little change in the size of the fibrovascular tissue over time and a final visual acuity similar for eyes with and without fibrovascular tissue. This group consequently questioned the usefulness of treatment in those eyes (Park et al., 1996). However, Engelbrecht and co-workers reported that $80 \%$ of eyes with proliferative MacTel type 2 had a final visual acuity of 20/200 or worse (Engelbrecht et al., 2002). Therefore, interventions might be most beneficial in early and active proliferative disease stages before the development of fibrotic membranes.

Visual improvement, stabilization and deterioration have all been reported after argon laser photocoagulation. The resulting scotoma and the potential to trigger further growth of neovascular membranes would not favor this treatment approach, even if the membranes were extrafoveal.

Photodynamic therapy (PDT) was first reported in a patient with recent decrease in visual acuity due to subretinal neovascularisation. Visual acuity improved 2 lines after two treatments and remained stable for seven months (Potter et al., 2002). Interestingly, leakage from the neovascular membrane ceased after treatment while parafoveal leakage typical for MacTel type 2 continued. Hershberger and co-workers needed five PDT sessions and achieved an improvement of visual acuity from initially 20/160 to 20/50 6 months after the last PDTsession in one eye of one patient (Hershberger et al., 2003). They noted a significant and rapid improvement in visual acuity following each treatment but also a rapid reperfusion of the neovascular membrane following PDT-induced closure. The group speculated that the first may be attributable to a relatively healthy pigment epithelium compared to other diseases in which PDT is used, such as age-related macular degeneration. The latter finding was explained by the high-flow anastomoses described in MacTel type 2. The largest series studying PDT for neovascular MacTel type 2, a retrospective analysis, described seven eyes of six patients (Potter et al., 2006). An average of 2.4 treatments were given according to a standard protocol (TAP-Study-Group, 1999). Mean follow-up time after the last treatment was 21 months and median initial and final visual acuity was $20 / 80$. More than 2 lines decrease or increase in visual acuity was observed in one eye each while the other 5 eyes remained stable. Snyers and co-workers reviewed 4 patients with neovascular MacTel type 2 treated with PDT (Snyers et al., 2004). In three patients, visual acuity remained stable at 20/30 and 20/40 after one, two and three sessions of PDT, respectively, within a follow up time of 23,21 and 9 months. In one eye, leakage persisted even after 4 sessions of PDT and visual acuity decreased from 20/50 to 20/200 despite absence of enlargement of the neovascular membrane. Hussain and co-workers treated six eyes of three patients three times at shorter interval ( 2 months) than usual. All eyes in this series had stable visual acuity after a median follow up time of 10 months (range 6-21 months). The researchers noted associated retinal pigment epithelium collateral damage in 
all six eyes of their study. There is the theoretical concern with PDT for MacTel type 2 that the photosensitizing drug may leak out of the retinal vessels in the macula and cause harm when it is activated (Hussain et al., 2005; Potter et al., 2002). Shanmugam et al. showed atrophy of the retinal pigment epithelium (along with a decrease in visual acuity) corresponding to the size of the laser spot (Shanmugam and Agarwal, 2005). However, others did not observe any side effects (Potter et al., 2002, 2006).

Few cases of MacTel type 2 treated with PDT combined with an intravitreal injection of either triamcinolone (Smithen and Spaide, 2004) or ranibizumab (Rishi et al., 2008; Ruys et al., 2007) have been reported. Combined PDT and intravitreal triamcinolone for neovascular MacTel type 2 resulted in an increase of visual acuity from 20/200 to 20/50 (Smithen and Spaide, 2004). Re-treatment due to recurrence of leakage was performed 9 months later and visual acuity 3 months thereafter was 20/60. As an additional finding, they reported a complete absence of telangiectasia after treatment. However, intravitreal injection of triamcinolone alone in the fellow nonproliferative eye revealed no marked functional or angiographic effect. Combined PDT and intravitreal ranibizumab injection was reported in two case reports. An improvement of visual acuity from 20/125 to 20/60 and stabilization thereafter was achieved within a follow up period of 9 months in one patient (Rishi et al., 2008) and stabilization was achieved in the second patient (Ruys et al., 2007). Only one PDT treatment with either one (Rishi et al., 2008) or two (Ruys et al., 2007) intravitreal injections were necessary.

Transpupillary thermotherapy (TTT) was used in an interventional case series by Shukla et al. (2004). One and three months after treatment, $46 \%$ and $85 \%$ respectively of 13 eyes showed complete regression of the neovascular membrane. After a mean follow up of 8.6 months (range 2-24.5 months), 12 eyes had inactive membranes; 1 of these 12 required two additional sessions of TTT. The median visual acuity remained stable compared with baseline. While there was a stable ( \pm 2 Snellen lines) visual acuity in 11 eyes, one patient improved and one patient worsened by 3 lines.

Posterior juxtascleral administration of anecortave acetate $(15 \mathrm{mg}$, 6-month retreatment interval) in five eyes of four patients was reported to result in stabilization or improvement of lesion size, resolution of leakage, and stabilization of vision (Eandi et al., 2006). One eye with a very short history of visual deterioration showed the best result with an increase of 3 lines in visual acuity within a follow up period of 12 months. Three other eyes showed an increase of two and one line or a decrease in one line within a follow up period of 24 months. Visual acuity did not change in one eye that was last said to be stable 9 months after the first treatment.

Intravitreal application of VEGF-inhibitors has become the first line treatment for neovascular membranes due to age-related macular degeneration (AMD). The concept of a similar pathogenesis of neovascular AMD and MacTel type 2 was the rationale to study VEGF-inhibitors as a treatment option for neovascular MacTel type 2 (Fig. 10; Charbel Issa et al., 2007b; Jorge et al., 2006; Karagiannis et al., 2009; Konstantinidis et al., 2009; Maia Junior et al., 2007; Mandal et al., 2007; Mondal et al., 2010; Roller et al., 2011; Ruys et al., 2007; Shanmugam et al., 2007). Jorge and co-workers were the first to show a positive effect of bevacizumab in a patient with a juxtafoveolar neovascular membrane (Jorge et al., 2006). They observed improvement of vision from 20/40 to 20/20 at 24 weeks of follow-up. Mandal presented a case series of six eyes of six patients treated with intravitreally injected bevacizumab (Mandal et al., 2007). The therapy was repeated at four weekly intervals if OCT showed persistent intraretinal edema and/or subretinal fluid. After a mean period of 4.2 months (range 3-6 months), visual acuity had improved by a mean of +2.5 except lines (range $0-+6$ lines) and all eyes one had two or more lines improvement. One eye without 
functional improvement exhibited retinal pigment hyperplasia involving the center of the fovea. More than one injection $(n=2)$ was only necessary in one eye. A decrease in retinal thickness and leakage was demonstrated by OCT imaging and fluorescein angiography, the latter also showing diminuation of leakage from telangiectatic vessels. Another retrospective case series ( 9 eyes) by Roller et al. also concluded that anti-VEGF treatment may be beneficial for proliferative MacTel type 2. Within a mean follow up of $17( \pm 9)$ months, 3 eyes improved $\geq 2$ lines, 2 eyes worsened by $\geq 2$ lines, and in 4 eyes visual acuity remained stable at the last follow-up compared with baseline. Patients needed $4.9( \pm 4.3$; range, $1-15)$ injections. In a third retrospective case series, 16 treatment-naïve eyes of 16 patients were treated with intravitreal ranibizumab or bevacizumab monotherapy (Narayanan et al., 2012). A mean of 1.9 injections (range, 1-3 injections) were needed during a mean follow up time of 12 months (range, 3-43 months). Mean visual acuity improved significantly from 20/120 to 20/70. Most other smaller case reports have demonstrated similar outcomes of intravitreally applied bevacizumab on the activity of neovascular membranes in MacTel type 2 .

Surgical removal of subfoveal vascular membranes in MacTel type 2 could not be performed without also removing pieces of neurosensory retina due to adherence of the membranes to the retinal vasculature (Berger et al., 1997; Davidorf et al., 2004). Since the functional outcome was unfavorable, it may be concluded that subretinal surgery with current techniques is not efficacious for proliferative MacTel type 2.

\section{Perspectives}

\subsection{Natural history and disease progression}

Since the landmark study by Gass and Blodi in 1993, little knowledge has been added on the phenotypic and functional changes of MacTel type 2 until recently. In the last several years, however, a large number of previously unknown findings have been identified by applying advanced imaging and functional testing. Thorough and valid evaluation of disease progression will be necessary not only to assess treatment effects in future therapeutic trials, but also to assess the natural history and eventually generate a more refined disease staging. Analysis of longitudinal data using new tools for disease phenotyping will help to identify outcome measures for interventional clinical trials as well as to stratify patients regarding their risk for disease progression. Longitudinal data will also reveal if patients can be stratified according to different disease characteristics into subgroups of fast or slow progressors, possibly according to different genetic backgrounds or environmental factors. There may also be variation in the individual pathophysiological response to the disease. For instance, the chronic low grade leakage due to an impaired blood-retinal barrier might trigger anti-retinal-antibodies in a subset of patients which might subsequently develop a faster or different disease progression.

The most widely accepted clinical endpoint in ophthalmology, visual acuity, appears not to be a sensitive marker for progression of MacTel type 2. Central retinal function, including distance visual acuity, may remain relatively intact over substantial periods of time even though other visual functions, such as reading ability and the size of paracentral scotomata, deteriorate (Fig. 9). However, the high variability of psychophysical testing results in difficult verification of functional deterioration in a slowly progressing disease such as MacTel type 2. Objective surrogate markers, e.g. derived from imaging analysis and structure-function correlation, might be helpful in this respect, at least for exploratory studies or for provisional drug approval. Since not all structural changes over time are functionally meaningful, such surrogate markers would need to be validated in independent studies against true clinical endpoints. 
A recent interventional study illustrates how relying on certain imaging modalities could be misleading in MacTel type 2: VEGF-inhibition over one year resulted in regression of the vascular alterations on fluorescein angiography and visual acuity, after a transient increase, was stable compared with baseline after one-year (see Chapter 13.1) (Charbel Issa et al., 2011). However, microperimetry rather showed a decrease in paracentral retinal sensitivity and point-to-point structure-function correlation revealed that functionally relevant alterations within the photoreceptor layer visible on spectral domain OCT progressed in treated eyes (Charbel Issa et al., 2010). Therefore, despite the apparently positive effect on fluorescein angiography and visual acuity testing, this therapy was not recommended. Notably, the atrophic changes in the photoreceptor layer as the structural correlate of the retinal sensitivity loss were already visible on spectral domain OCT before their functional relevance could be detected by microperimetry (Charbel Issa et al., 2010).

\subsection{Understanding clinical findings}

14.2.1. Macular pigment distribution and crystalline deposits-The reduced macular pigment density within the central retina is one of the most striking features of MacTel type 2. The lack of its function as a blue light filter could result in increased light damage of macular photoreceptors. In MacTel type 2, a primary loss of macular pigment due to defective trafficking or storage (e.g. due to dysfunctional transport proteins), or a secondary loss due to pathology of the anatomical structures involved in macular pigment accumulation, have been suggested. It remains to be determined if macular pigment is simply reduced centrally or if there is (additional) displacement of macular pigment towards the periphery. The latter is suggested by the appearance on two-wavelength fundus AF maps in advanced cases and by the significantly higher density at $8^{\circ}$ eccentricity in a quantitative analysis (Charbel Issa et al., 2009d). However, the sample size in that study was small and there were no normal data available for $6^{\circ}$ eccentricity where the macular pigment density appears to be highest in many patients with MacTel type 2. In a recent study, the total amount of macular pigment was calculated using a more eccentric reference area than the conventional $8^{\circ}$ (Degli Esposti et al., 2012). The authors found values comparable to normal controls, suggesting that lutein and zeaxanthin are actually not lost from the posterior fundus, but rather displaced laterally to a certain extent. Longitudinal data studying the evolution and progression of macular pigment loss in MacTel type 2 patients are so far lacking.

Since MacTel type 2 shares structural features with retinal dystrophies, assessment of macular pigment density and distribution in patients with other macular dystrophies may help to further understand this finding. Loss of macular pigment may be considered a secondary phenomenon if it occurs uniformly in unrelated diseases. Recently, absence of macular pigment has been reported in patients with Sjögren-Larsson-Syndrome (van der Veen et al., 2010). The known deficiency of fatty aldehyde dehydrogenase in patients with this disease may suggest possible pathogenetic pathways involved in the lack of macular pigment. Notably, patients with Sjögren-Larsson-Syndrome also show crystalline deposits and changes on OCT imaging (see Chapter 13.2) similar to those observed in patients with MacTel type 2. Moreover, similar deposits and OCT-changes have been reported for patients with Tamoxifen retinopathy, for which no data on macular pigment distribution have yet been published. Tamoxifen was suggested to inhibit glutamate uptake into retinal pigment epithelial cells. Increased concentrations of glutamate in the extracellular retinal space might lead to excitatory toxicity with subsequent cell death. Experimental data are available for Canthaxanthin retinopathy which also shows similar crystalline deposits, although in a slightly different distribution. In the monkey retina, the amount of the carotenoid canthaxanthin and its metabolites in retinal tissue correlated with the amount of ophthalmoscopically visible crystalline deposits, strongly suggesting that these crystals 
indeed are due to a high load of this carotenoid (Goralczyk et al., 2000, 1997). A histopathological investigation of a human eye with canthaxanthin retinopathy also suggested that carotenoids are involved in the pathogenesis of the crystalline deposits (Daicker et al., 1987). Notably, there was also atrophy of the inner parts of Müller cells (see Chapter 14.3).

Because the lack of macular pigment is localized and not absolute, as in Sjögren-LarssonSyndrome, it is unlikely that a systemic alteration leads to a primary loss of macular pigment in the retina in MacTel type 2, although the involved area might be most vulnerable to such an insult. It appears more likely that structural alterations lead to a localized loss of macular pigment, which then - hypothetically - may be converted into its crystalline form.

Further research into the pathophysiology of MacTel type 2 is likely to benefit research on the so far incompletely understood mechanisms of macular pigment accumulation in the central retina. Vice versa, a better knowledge of the physiological mechanisms and anatomical structures involved in accumulation, trafficking and storage of lutein and zeaxanthin in the central retina may shed light on the pathophysiology of MacTel type 2. Interestingly, two binding proteins for macular pigments, namely Glutathione S-transferase $\mathrm{Pi}$ isoform (GSTP1) for zeaxanthin and human retinal lutein-binding protein (HR-LBP) for lutein were recently identified (Bhosale et al., 2004, 2009; Li et al., 2011).

Immunohistochemical studies showed specific labeling for both binding proteins of rod and cone inner segments, especially in the mitochondria-rich ellipsoid region. Since OCT studies in patients with MacTel type 2 suggested this retinal layer to be affected early in the disease course (see Chapter 6.2), alterations in the metabolically active compartment of photoreceptors (whether primary or secondary) may play a major role in the pathogenesis of MacTel type 2. Additional strong labeling with anti-GSTP1 was found in the outer plexiform layer (Henle's fiber layer). Recently, polymorphisms in the GSTP1 gene were looked at in MacTel type 2 patients but no obvious association was found (Parmalee et al., 2010; Szental et al., 2010).

Questions to be answered with regard to the characteristic distribution of macular pigment in patients with MacTel type 2 will include: Does the expression of lutein and zeaxanthinbinding proteins in photoreceptors point to a primary photoreceptor disease? Are specialized Müller cells involved in the accumulation and/or storage of lutein and zeaxanthin in the central retina? What is the anatomic or physiological correlate that defines the characteristic area of macular pigment loss?

14.2.2. Primarily neurosensory or vascular disease?-Hyporeflective atrophic cavities of the neurosensory retina have been reported in patients with inherited retinal dystrophies (Barthelmes et al., 2008b; Kellner and Kellner, 2009; Mahajan et al., 2009), suggesting a similar disease process also for MacTel type 2. With regard to the inner hyporeflective cavities, there may be a loss of retinal structural integrity possibly similar to $\mathrm{X}$-linked retinoschisis. In the absence of a bullous central retinal schisis, OCT findings in Xlinked retinoschisis may actually resemble those in MacTel type 2 (Gerth et al., 2008; Gregori et al., 2009), and the respective knock-out mouse model reveals pathologic features reminiscent of MacTel type 2 (Weber et al., 2002).

The atrophy of the outer neurosensory retina which is primarily supplied by the choroid, the localized loss of macular pigment which has not been reported to occur in other retinal vascular disease, and the larger size of areas of macular pigment loss compared with angiographically visible vascular alterations all do not support a primarily vascular disease process. The eponymous and characteristic ectatic parafoveolar capillaries may represent a secondary phenomenon, e.g. due to localized metabolic and/or oxidative stress within the 
outer retina that could result in an increased expression of VEGF. This could lead to the development of ectatic and sprouting capillaries along a concentration gradient towards the outer retina. A medical history that may lead to similar vascular alterations (e.g. diabetic or radiation retinopathy) and that may render capillaries especially sensitive to the effects of VEGF might predispose to such vascular telangiectatic alterations. Accordingly, some studies identified diabetes mellitus, a pathologically decreased glucose tolerance as well as a history of radiation exposure to be associated with MacTel type 2 (Chew et al., 1986; Maberley et al., 1999; Millay et al., 1986). It may be speculated that similar neurosensory atrophic alterations may occur with varying vascular alterations depending on additional factors that modify the susceptibility to develop the vascular phenotype.

14.2.3. Area of disease manifestation-Several hypotheses were put forward to explain the restriction and/or predilection of the MacTel type 2-associated pathology to the peculiar area that it affects. For instance, it was suggested that the presence of more numerous arterio-venous crossings temporal to the fovea compared with nasally might give rise to chronic low grade congestion or venous stasis of the temporal paramacular capillaries (Gass and Oyakawa, 1982). However, a similar vascular pattern was identified in 43 of 54 randomly selected control eyes. Watzke et al. (2005) suggested a developmental origin based on the findings that the vessels in the temporal paramacular area were formed by anastomoses of superior and inferior vessels and not by extension, as were all other retinal vessels (Nishimura and Taniguchi, 1982). This could cause structural abnormalities with subsequent decompensation of these vessels in adult life.

The reason for the temporal predilection may not necessarily be found in the retinal vasculature. If the vascular alterations are a secondary feature in the pathophysiology of the disease, any proposed mechanism would have to explain why a primarily atrophic disease process would be restricted to or most pronounced within this area. Notably, the retinal area involved in MacTel type 2 is similar to the localization of changes in other macular dystrophies without vascular pathology (Kurz-Levin et al., 2002; Michaelides et al., 2007). The underlying cause for the affection of this particular area as well as the temporal predilection is, however, still unknown.

\subsection{The role of Müller cells}

Through the extensive arborization of their processes, Müller cells provide nutritional and regulatory support to both retinal neurons and vascular cells. They are intimately connected with cone photoreceptors through microvilli extending from the outer limiting membrane. In the glycolytic pathway, Müller cells convert glucose into lactate which they supply to the highly energy-demanding photoreceptors. In retinal disease, Müller cells may protect photoreceptors through the release of neurotrophic factors, such as nerve growth factor (NGF), brain-derived neurotrophic factor (BDNF), neurotrophins (NT-3 and -4) and ciliary neurotrophic factor (CNTF) and the antioxidant glutathione (Bringmann et al., 2009, 2006). They express GLAST, the predominant transporter within the retina for the removal of the excitotoxic neurotransmitter glutamate. Müller cells are also involved in the formation and maintenance of the blood-retinal barrier (BRB), which they may influence by the secretion of other factors such as pigment epithelium derived factor (PEDF) and VEGF (Bringmann et al., 2006). The involvement of Müller cells in supporting both neurons and vasculature suggests that their dysfunction may be a central, although not necessarily primary, feature of MacTel type 2, which is characterized mainly by dysfunction of these two retinal elements.

Results from a clinico-pathological analysis of a pair of eyes obtained post mortem from a confirmed case of MacTel type 2 (Powner et al., 2010) support this hypothesis (see Chapter 11). The distribution of loss of Müller cell specific immunohistological markers correlated 
closely with the loss of macular pigment, a phenotypic hallmark in patients with MacTel type 2. Macular pigment is located in Henle's layer (Snodderly et al., 1984a, 1984b; Trieschmann et al., 2008), but whether it is associated with nerve fibers of photoreceptors or Müller cell processes remains unknown. Macular pigment appeared to persist when primate photoreceptors were ablated by subretinal alpha-aminoadipic acid in a primate study, suggesting that at least some of the pigment may reside in Müller cells, which were relatively unaffected in this model (Shen et al., 2011). Analysis of the central retina from the fellow eye of this pair using proteomic techniques revealed reduced levels of Müller cellspecific proteins, including glial fibrillary acid protein, vimentin and glutamine synthetase (Len et al., 2012).

A number of clinical features of MacTel type 2 could be consistent with a central Müller cell defect. As mentioned above, some observations suggest - albeit circumstantially - that loss of macular pigment could be associated with Müller cell dysfunction. Loss of retinal transparency might also be associated with Müller cell dysfunction, particularly if they act as light pipes that transmit light through the retina as suggested by Franze et al. (2007).

Further studies, including the development of appropriate animal models (see below), are warranted to test the hypothesis that Müller cell loss and/or dysfunction may play a causative role in the pathogenesis of MacTel type 2.

\subsection{Animal models}

Due to their apparent role in the disease pathophysiology, Müller cells became a target in the development of new animal models for MacTel type 2, Shen et al. generated a transgenic mouse model of conditional Müller cell ablation using a Müller cell-specific promoter to drive the expression of an attenuated form of diphtheria toxin fragment A (DTA176). The retina in this model showed a rapid photoreceptor apoptosis, vascular telangiectasia, a blooderetinal barrier and breakdown later also deep retinal neovascularization (Shen et al., 2012). Khalid et al. reported the effect of Müller cell drop out after cell-specific transduction of a gene expressing an inducible toxic protein (Khalid FI, IOVS 2012, ARVO E-Abstract \#1640). The procedure resulted in structural damage and compromised retinal function. Thus, both mouse models of Müller cell ablation showed findings reminiscent of MacTel type 2 in humans.

Other animal models with similar retinal alterations may add to the understanding of the pathogenesis of MacTel type 2. Transgenic mouse models with over-expression of VEGF in photoreceptor cells share overexpression of VEGF as well as neurosensory alterations similar to the findings in patients (Lai et al., 2005; Okamoto et al., 1997; Tobe et al., 1998; van Eeden et al., 2006), including outer retinal degeneration, ectatic capillaries, sprouting of retinal vessels into the outer neurosensory retina, angiographically detectable leakage from retinal vessels and neovascular membranes originating from the same vasculature. A mouse with a defect in the gene for very low density lipoprotein receptor also develops some features similar to MacTel type 2 (Dorrell et al., 2009; Heckenlively et al., 2003). Deep retinal neovascularisation arising from the retinal vasculature is prominent in this model. Photoreceptor cell death associated with the neovascularisation was inhibited by both antioxidants and cell-based delivery of neurotrophic factors (Dorrell et al., 2009).

\subsection{Potential therapeutic approaches}

Since loss of photoreceptors appears to be the main cause for the loss of vision in MacTel type 2 , treatment to prevent progression of the condition may be aimed at preventing photoreceptor loss. Ciliary neurotrophic factor (CNTF) is one of several neurotrophic factors that are produced endogenously by Müller cells. Several studies have suggested that CNTF 
may be potentially therapeutic for retinal disorders (MacDonald et al., 2007). It has been shown to protect the photoreceptors from degeneration in a variety of animal models of retinitis pigmentosa, such as rd mice (Cayouette and Gravel, 1997; LaVail et al., 1998), rds/ rds mice, 334ter-3 rats, 334ter-4 rats, P23H-1 rats, Rdy cats and rcd1dogs (Bok et al., 2002; Cayouette et al., 1998; Chong et al., 1999; LaVail et al., 1998; Liang et al., 2001; Tao et al., 2002). There is already evidence that CNTF might be beneficial in human retinal degenerative disease as shown recently in a phase $\mathrm{Ib}$ trial in retinitis pigmentosa (Sieving et al., 2006). Currently, a phase $1 \mathrm{~b}$ clinical trial is underway to investigate the safety of intravitreal CNTF for the application in MacTel type 2 (ClinicalTrials.gov Identifier: NCT01327911).

\section{Summary and future directions}

Macular telangiectasia (MacTel) type 2 is a neurodegenerative disease affecting the central retina. There has been remarkable progress in characterizing the disease and revealing its pathophysiology. General progress in phenotyping and therapy for retinal disease has helped tremendously to study MacTel type 2. Examples are imaging studies using high-resolution OCT and confocal laser scanning ophthalmoscopy, fundus-controlled perimetry, and intravitreal pharmacotherapy. So far, no therapy has been shown to be efficacious to modify the slow photoreceptor loss characteristic for the disease. While efficacy of anti-VEGF therapy has not been shown in the non-proliferative disease, there may be a benefit for patients with neovascular disease manifestation. MacTel type 2 shows some unique features such as a central reduction of macular pigment and hyporeflective cavities at the level of the inner and outer retina as observed with high-resolution OCT imaging. Such characteristic features provide further clues for the development of future therapy. Since the condition appears to be primarily neurodegenerative in nature, therapeutic interventions with compounds that have neuroprotective properties appear promising. An interventional clinical trial in Mactel type 2, making use of neuroprotection is currently underway.

\section{Acknowledgments}

Supported by the Lowy Medical Research Institute (The Macular Telangiectasia Project, www.mactelresearch.com); Pro-Retina Deutschland (P.C.I.); Wynn-Gund Translational Research Acceleration Program Enhanced Research and Clinical Training Award, National Neurovision Research Institute (NNRI) Foundation Fighting Blindness (FFB; NNCD-CL-0310.0049-JHU-WG); Macular Degeneration Research Award, American Health Assistance Foundation (AHAF; M2010042); Unrestricted grant to the Wilmer Eye Institute from Research to Prevent Blindness; Baylor-Johns Hopkins Center for Mendelian Genetics (National Human Genome Research Institute, NHGRI/NIH; Identification number: 1U54HG006542-01). H.P.N.S. is the Dr. Frieda Derdeyn Bambas Professor of Ophthalmology. None of the authors has a conflict of interest.

\section{Abbreviations}
AF
autofluorescence
MacTel
macular telangiectasia
OCT
optical coherence tomography
PDT
photodynamic therapy
VEGF
vascular endothelial growth factor

\section{References}

Ablonczy Z, Crosson CE. VEGF modulation of retinal pigment epithelium resistance. Exp. Eye Res. 2007; 85:762-771. [PubMed: 17915218] 
Abujamra S, Bonanomi MT, Cresta FB, Machado CG, Pimentel SL, Caramelli CB. Idiopathic juxtafoveolar retinal telangiectasis: clinical pattern in 19 cases. Ophthalmologica. 2000; 214:406411. [PubMed: 11054001]

Albini TA, Benz MS, Coffee RE, Westfall AC, Lakhanpal RR, McPherson AR, Holz ER. Optical coherence tomography of idiopathic juxtafoveolar telangiectasia. Ophthalmic Surg. Lasers Imaging. 2006; 37:120-128. [PubMed: 16583633]

Alldredge CD, Garretson BR. Intravitreal triamcinolone for the treatment of idiopathic juxtafoveal telangiectasis. Retina. 2003; 23:113-116. [PubMed: 12652245]

Arevalo JF, Sanchez JG, Garcia RA, Wu L, Berrocal MH, Rodriguez FJ, Rodriguez A, Novoa LA, Garcia-Amaris R. Indocyanine-green-mediated photothrombosis (IMP) with intravitreal triamcinolone acetonide for macular edema secondary to group 2A idiopathic parafoveal telangiectasis without choroidal neovascularization: a pilot study. Graefes Arch. Clin. Exp. Ophthalmol. 2007; 245:1673-1680. [PubMed: 17619895]

Aung KZ, Wickremasinghe SS, Makeyeva G, Robman L, Guymer RH. The prevalence estimates of macular telangiectasia Type 2: the Melbourne Collaborative Cohort Study. Retina. 2010; 30:473478. [PubMed: 19952995]

Bakke EF, Drolsum L. Iris microhaemangiomas and idiopathic juxtafoveolar retinal telangiectasis. Acta Ophthalmol. Scand. 2006; 84:818-822. [PubMed: 17083546]

Barthelmes D, Gillies MC, Fleischhauer JC, Sutter FK. A case of idiopathic perifoveal telangiectasia preceded by features of cone dystrophy. Eye. 2007; 21:1534-1535. [PubMed: 17891056]

Barthelmes D, Gillies MC, Sutter FK. Quantitative OCT analysis of idiopathic perifoveal telangiectasia. Invest. Ophthalmol. Vis. Sci. 2008a; 49:2156-2162. [PubMed: 18436849]

Barthelmes D, Sutter FK, Gillies MC. Differential optical densities of intraretinal spaces. Invest. Ophthalmol. Vis. Sci. 2008b; 49:3529-3534. [PubMed: 18441298]

Baumüller S, Charbel Issa P, Scholl HP, Schmitz-Valckenberg S, Holz FG. Outer retinal hyperreflective spots on spectral-domain optical coherence tomography in macular telangiectasia type 2. Ophthalmology. 2010; 117:2162-2168. [PubMed: 20557944]

Berger AS, McCuen BW, Brown GC, Brownlow RL Jr. Surgical removal of subfoveal neovascularization in idiopathic juxtafoveolar retinal telangiectasis. Retina. 1997; 17:94-98. [PubMed: 9143035]

Bhosale P, Larson AJ, Frederick JM, Southwick K, Thulin CD, Bernstein PS. Identification and characterization of a Pi isoform of glutathione S-transferase (GSTP1) as a zeaxanthin-binding protein in the macula of the human eye. J. Biol. Chem. 2004; 279:49447-49454. [PubMed: 15355982]

Bhosale P, Li B, Sharifzadeh M, Gellermann W, Frederick JM, Tsuchida K, Bernstein PS. Purification and partial characterization of a lutein-binding protein from human retina. Biochemistry. 2009; 48:4798-4807. [PubMed: 19402606]

Bok D, Yasumura D, Matthes MT, Ruiz A, Duncan JL, Chappelow AV, Zolutukhin S, Hauswirth W, LaVail MM. Effects of adeno-associated virus-vectored ciliary neurotrophic factor on retinal structure and function in mice with a P216L rds/peripherin mutation. Exp. Eye Res. 2002; 74:719735. [PubMed: 12126945]

Bottoni F, Eandi CM, Pedenovi S, Staurenghi G. Integrated clinical evaluation of type 2a idiopathic juxtafoveolar retinal telangiectasis. Retina. 2010; 30:317-326. [PubMed: 19881399]

Bringmann A, Pannicke T, Grosche J, Francke M, Wiedemann P, Skatchkov SN, Osborne NN, Reichenbach A. Muller cells in the healthy and diseased retina. Prog. Retin. Eye Res. 2006; 25:397-424. [PubMed: 16839797]

Bringmann A, Iandiev I, Pannicke T, Wurm A, Hollborn M, Wiedemann P, Osborne NN, Reichenbach A. Cellular signaling and factors involved in Müller cell gliosis: neuroprotective and detrimental effects. Prog. Retin. Eye Res. 2009; 28:423-451. [PubMed: 19660572]

Bruè C, Tseng JJ, Barbazetto I, Lima LH, Yannuzzi LA. Peculiar manifestation of macular telangiectasia type 2. Retin. Cases Brief Rep. 2011; 5:309-312.

Cahill M, O'Keefe M, Acheson R, Mulvihill A, Wallace D, Mooney D. Classification of the spectrum of Coats' disease as subtypes of idiopathic retinal telangiectasis with exudation. Acta Ophthalmol. Scand. 2001; 79:596-602. [PubMed: 11782226] 
Cakir M, Kapran Z, Basar D, Utine CA, Eroglu F, Perente I. Optical coherence tomography evaluation of macular edema after intravitreal triamcinolone acetonide in patients with parafoveal telangiectasis. Eur. J. Ophthalmol. 2006; 16:711-717. [PubMed: 17061222]

Casswell AG, Chaine G, Rush P, Bird AC. Paramacular telangiectasis. Trans. Ophthalmol. Soc. U.K. 1986; 105(Pt 6):683-692. [PubMed: 3477896]

Cayouette M, Gravel C. Adenovirus-mediated gene transfer of ciliary neurotrophic factor can prevent photoreceptor degeneration in the retinal degeneration (rd) mouse. Hum. Gene Ther. 1997; 8:423430. [PubMed: 9054517]

Cayouette M, Behn D, Sendtner M, Lachapelle P, Gravel C. Intraocular gene transfer of ciliary neurotrophic factor prevents death and increases responsiveness of rod photoreceptors in the retinal degeneration slow mouse. J. Neurosci. 1998; 18:9282-9293. [PubMed: 9801367]

Charbel Issa P, Helb HM, Rohrschneider K, Holz FG, Scholl HPN. Microperimetric assessment of patients with type II macular telangiectasia. Invest. Ophthalmol. Vis. Sci. 2007a; 48:3788-3795. [PubMed: 17652753]

Charbel Issa P, Holz FG, Scholl HPN. Findings in fluorescein angiography and optical coherence tomography after intravitreal bevacizumab in type 2 idiopathic macular telangiectasia. Ophthalmology. 2007b; 114:1736-1742. [PubMed: 17822979]

Charbel Issa, P.; Scholl, HPN.; Helb, HM.; Holz, FG. Idiopathic macular telangiectasia. In: Holz, FG.; Spaide, RF., editors. Medical Retina. Springer; Berlin, Heidelberg: 2007c. p. 183-197.

Charbel Issa P, Scholl HPN, Holz FG. Intravitreal bevacizumab for the treatment of type 2 idiopathic macular telangiectasis. Retin. Cases Brief Rep. 2007d; 1:189-191.

Charbel Issa P, Berendschot TT, Staurenghi G, Holz FG, Scholl HP. Confocal blue reflectance imaging in type 2 idiopathic macular telangiectasia. Invest. Ophthalmol. Vis. Sci. 2008a; 49:11721177. [PubMed: 18326746]

Charbel Issa P, Finger RP, Holz FG, Helb HM, Scholl HPN. A new diagnostic approach in patients with type 2 macular telangiectasia: confocal reflectance imaging. Acta Ophthalmol. Scand. 2008b; 86:464-465.

Charbel Issa P, Finger RP, Holz FG, Scholl HPN. Eighteen-month follow-up of intravitreal bevacizumab in type 2 idiopathic macular telangiectasia. Br. J. Ophthalmol. 2008c; 92:941-945. [PubMed: 18577646]

Charbel Issa P, Helb HM, Holz FG, Scholl HPN, on behalf of the MacTel Study, G. Correlation of macular function with retinal thickness in nonproliferative type 2 idiopathic macular telangiectasia. Am. J. Ophthalmol. 2008d; 245:169-175. [PubMed: 17981256]

Charbel Issa P, Holz FG, Scholl HP. The article by Kovach and Rosenfeld. Retina. 2009a; 29:717718. [PubMed: 19430284]

Charbel Issa P, Holz FG, Scholl HPN. Metamorphopsia in patients with macular telangiectasia type 2. Doc. Ophthalmol. 2009b; 119:133-140. [PubMed: 19711108]

Charbel Issa P, Scholl HP, Gaudric A, Massin P, Kreiger AE, Schwartz S, Holz FG. Macular fullthickness and lamellar holes in association with type 2 idiopathic macular telangiectasia. Eye. 2009c; 23:435-441. [PubMed: 18259211]

Charbel Issa P, van der Veen RLP, Stifjs A, Holz FG, Scholl HPN, Berendschot TTJM. Quantification of reduced macular pigment optical density in the central retina in macular telangiectasia type 2. Exp. Eye Res. 2009d; 89:25-31. [PubMed: 19233170]

Charbel Issa P, Tröger E, Finger R, Holz FG, Wilke R, Scholl HPN. Structure-function correlation of the human central retina. PLoS One. 2010; 5:e12864. [PubMed: 20877651]

Charbel Issa P, Finger RP, Kruse K, Baumüller S, Scholl HP, Holz FG. Monthly ranibizumab for nonproliferative macular telangiectasia type 2: a 12-month prospective study. Am. J. Ophthalmol. 2011; 151:876-886. [PubMed: 21334595]

Cherepanoff S, Killingsworth MC, Zhu M, Nolan T, Hunyor AP, Young SH, Hageman GS, Gillies MC. Ultrastructural and clinical evidence of subretinal debris accumulation in type 2 macular telangiectasia. Br. J. Ophthalmol. 2012; 96(11):1404-1409. [PubMed: 22976584]

Chew EY, Murphy RP, Newsome DA, Fine SL. Parafoveal telangiectasis and diabetic retinopathy. Arch. Ophthalmol. 1986; 104:71-75. [PubMed: 3942547] 
Chong NHV, Alexander RA, Waters L, Barnett KC, Bird AC, Luthert PJ. Repeated injections of a ciliary neurotrophic factor analogue leading to long-term photoreceptor survival in hereditary retinal degeneration. Invest. Ophthalmol. Vis. Sci. 1999; 40:1298-1305. [PubMed: 10235570]

Chopdar A. Retinal telangiectasis in adults: fluorescein angiographic findings and treatment by argon laser. Br. J. Ophthalmol. 1978; 62:243-250. [PubMed: 565649]

Clemons TE, Gillies MC, Chew EY, Bird AC, Peto T, Figueroa M, Harrington MW. The National Eye Institute Visual Function Questionnaire in the Macular Telangiectasia (MacTel) Project. Invest. Ophthalmol. Vis. Sci. 2008; 49:4340-4346. [PubMed: 18586874]

Clemons TE, Gillies MC, Chew EY, Bird AC, Peto T, Figueroa MJ, Harrington MW. Baseline characteristics of participants in the natural history study of macular telangiectasia (MacTel) MacTel Project Report No. 2. Ophthalmic Epidemiol. 2010; 17:66-73. [PubMed: 20100102]

Costa RA, Skaf M, Melo LA Jr. Calucci D, Cardillo JA, Castro JC, Huang D, Wojtkowski M. Retinal assessment using optical coherence tomography. Prog. Retin. Eye Res. 2006; 25:325-353. [PubMed: 16716639]

Daicker B, Schiedt K, Adnet JJ, Bermond P. Canthaxanthin retinopathy. An investigation by light and electron microscopy and physicochemical analysis. Graefes Arch. Clin. Exp. Ophthalmol. 1987; 225:189-197. [PubMed: 3111944]

Davidorf FH, Pressman MD, Chambers RB. Juxtafoveal telangiectasisa name change? Retina. 2004; 24:474-478. [PubMed: 15187680]

Davies NP, Morland AB. Macular pigments: their characteristics and putative role. Prog. Retin. Eye Res. 2004; 23:533-559. [PubMed: 15302350]

De Lahitte GD, Cohen SY, Gaudric A. Lack of apparent short-term benefit of photodynamic therapy in bilateral, acquired, parafoveal telangiectasis without subretinal neovascularization. Am. J. Ophthalmol. 2004; 138:892-894. [PubMed: 15531343]

Degli Esposti S, Egan C, Bunce C, Moreland JD, Bird A, Robson AG. Macular pigment parameters in patients with macular telangiectasia (MacTel) and normal subjects; implications of a novel analysis. Invest. Ophthalmol. Vis. Sci. 2012; 53:6568-6575. [PubMed: 22899764]

Delaere L, Spielberg L, Leys A. Vertical transmission of macular telangiectasia type 2. Retin. Cases Brief Rep. 2011; 6:253-257.

Delori FC, Dorey CK, Staurenghi G, Arend O, Goger DG, Weiter JJ. In vivo fluorescence of the ocular fundus exhibits retinal pigment epithelium lipofuscin characteristics. Invest. Ophthalmol. Vis. Sci. 1995; 36:718-729. [PubMed: 7890502]

Dorrell MI, Aguilar E, Jacobson R, Yanes O, Gariano R, Heckenlively J, Banin E, Ramirez GA, Gasmi M, Bird A, Siuzdak G, Friedlander M. Antioxidant or neurotrophic factor treatment preserves function in a mouse model of neovascularization-associated oxidative stress. J. Clin. Invest. 2009; 119:611-623. [PubMed: 19188685]

Drenser K, Sarraf D, Jain A, Small KW. Crystalline retinopathies. Surv. Ophthalmol. 2006; 51:535549. [PubMed: 17134644]

Eandi CM, Ober MD, Freund KB, Klais CM, Slakter JS, Sorenson JA, Yannuzzi LA. Anecortave acetate for the treatment of idiopathic perifoveal telangiectasia: a pilot study. Retina. 2006; 26:780-785. [PubMed: 16963851]

Eliassi-Rad B, Green WR. Histopathologic study of presumed parafoveal telangiectasis. Retina. 1999; 19:332-335. [PubMed: 10458300]

Engelbrecht NE, Aaberg TM Jr. Sung J, Lewis ML. Neovascular membranes associated with idiopathic juxtafoveolar telangiectasis. Arch. Ophthalmol. 2002; 120:320-324. [PubMed: 11879135]

Finger RP, Charbel Issa P, Fimmers R, Holz FG, Rubin GS, Scholl HPN. Reading performance is reduced due to parafoveal scotomas in patients with macular telangiectasia type 2. Invest. Ophthalmol. Vis. Sci. 2009; 50:1366-1370. [PubMed: 18997085]

Fitzsimons RB, Gurwin EB, Bird AC. Retinal vascular abnormalities in facioscapulohumeral muscular dystrophy. A general association with genetic and therapeutic implications. Brain. 1987; 110(Pt 3): 631-648. [PubMed: 3580827] 
Franze K, Grosche J, Skatchkov SN, Schinkinger S, Foja C, Schild D, Uckermann O, Travis K, Reichenbach A, Guck J. Müller cells are living optical fibers in the vertebrate retina. Proc. Natl. Acad. Sci. U. S. A. 2007; 104:8287-8292. [PubMed: 17485670]

Friedman SM, Mames RN, Stewart MW. Subretinal hemorrhage after grid laser photocoagulation for idiopathic juxtafoveolar retinal telangiectasis. Ophthalmic Surg. 1993; 24:551-553. [PubMed: 8233321]

Fuijkschot J, Cruysberg JR, Willemsen MA, Keunen JE, Theelen T. Subclinical changes in the juvenile crystalline macular dystrophy in Sjogren-Larsson syndrome detected by optical coherence tomography. Ophthalmology. 2008; 115:870-875. [PubMed: 17826835]

Gamulescu MA, Walter A, Sachs H, Helbig H. Bevacizumab in the treatment of idiopathic macular telangiectasia. Graefes Arch. Clin. Exp. Ophthalmol. 2008; 246:1189-1193. [PubMed: 18386039]

Gass JD. A fluorescein angiographic study of macular dysfunction secondary to retinal vascular disease. V. Retinal telangiectasis. Arch. Ophthalmol. 1968; 80:592-605. [PubMed: 5684308]

Gass, JDM. Stereoscopic Atlas of Macular Diseases. second ed.. Mosby; St. Louis: 1977.

Gass JD, Blodi BA. Idiopathic juxtafoveolar retinal telangiectasis. Update of classification and followup study. Ophthalmology. 1993; 100:1536-1546. [PubMed: 8414413]

Gass JD, Oyakawa RT. Idiopathic juxtafoveolar retinal telangiectasis. Arch. Ophthalmol. 1982; 100:769-780. [PubMed: 7082207]

Gaudric A, Ducos de LG, Cohen SY, Massin P, Haouchine B. Optical coherence tomography in group 2A idiopathic juxtafoveolar retinal telangiectasis. Arch. Ophthalmol. 2006; 124:1410-1419. [PubMed: 17030708]

Gerrits HJ, Timmerman GJ. The filling-in process in patients with retinal scotomata. Vision Res. 1969; 9:439-442. [PubMed: 5822961]

Gerth C, Zawadzki RJ, Werner JS, Heon E. Retinal morphological changes of patients with X-linked retinoschisis evaluated by Fourier-domain optical coherence tomography. Arch. Ophthalmol. 2008; 126:807-811. [PubMed: 18541843]

Gillies MC, Zhu M, Chew EY, Barthelmes D, Hughes E, Ali H, Holz FG, Scholl HPN, Charbel Issa P. Familial asymptomatic macular telangiectasia type 2. Ophthalmology. 2009; 116:2422-2429. [PubMed: 19815294]

Goralczyk R, Buser S, Bausch J, Bee W, Zuhlke U, Barker FM. Occurrence of birefringent retinal inclusions in cynomolgus monkeys after high doses of canthaxanthin. Invest. Ophthalmol. Vis. Sci. 1997; 38:741-752. [PubMed: 9071228]

Goralczyk R, Barker FM, Buser S, Liechti H, Bausch J. Dose dependency of canthaxanthin crystals in monkey retina and spatial distribution of its metabolites. Invest. Ophthalmol. Vis. Sci. 2000; 41:1513-1522. [PubMed: 10798671]

Green WR, Quigley HA, de la CZ, Cohen B. Parafoveal retinal telangiectasis. Light and electron microscopy studies. Trans. Ophthalmol. Soc. U.K. 1980; 100:162-170. [PubMed: 6943823]

Gregori N, Flynn HW Jr. Surgery for full-thickness macular hole in patients with idiopathic macular telangiectasia type 2. Ophthalmic Surg. Lasers Imaging. 2010; 41:1-4. Online. [PubMed: 21158375]

Gregori NZ, Berrocal AM, Gregori G, Murray TG, Knighton RW, Flynn HW Jr. Dubovy S, Puliafito CA, Rosenfeld PJ. Macular spectral-domain optical coherence tomography in patients with X linked retinoschisis. Br. J. Ophthalmol. 2009; 93:373-378. [PubMed: 19019942]

Gualino V, Cohen SY, Delyfer MN, Sahel JA, Gaudric A. Optical coherence tomography findings in tamoxifen retinopathy. Am. J. Ophthalmol. 2005; 140:757-758. [PubMed: 16226541]

Gurwin EB, Fitzsimons RB, Sehmi KS, Bird AC. Retinal telangiectasis in facioscapulohumeral muscular dystrophy with deafness. Arch. Ophthalmol. 1985; 103:1695-1700. [PubMed: 4062636]

Hannan SR, Madhusudhana KC, Rennie C, Lotery AJ. Idiopathic juxtafoveolar retinal telangiectasis in monozygotic twins. Br. J. Ophthalmol. 2007; 91:1729-1730. [PubMed: 18024833]

Heckenlively JR, Hawes NL, Friedlander M, Nusinowitz S, Hurd R, Davisson M, Chang B. Mouse model of subretinal neovascularization with choroidal anastomosis. Retina. 2003; 23:518-522. [PubMed: 12972764] 
Helb HM, Charbel Issa P, van der Veen RLP, Berendschot TTJM, Scholl HPN, Holz FG. Macular pigment density and distribution in patients with type II macular telangiectasia. Retina. 2008; 28:808-816. [PubMed: 18536596]

Hershberger VS, Hutchins RK, Laber PW. Photodynamic therapy with verteporfin for subretinal neovascularization secondary to bilateral idiopathic acquired juxtafoveolar telangiectasis. Ophthalmic Surg. Lasers Imaging. 2003; 34:318-320. [PubMed: 12875464]

Hogan, H.; Alvarado, JA.; Wedell, JE. Histology of the Human Eye: an Atlas and Textbook. W.B. Saunders; Philadelphia: 1971.

Hussain N, Das T, Sumasri K, Ram LS. Bilateral sequential photodynamic therapy for sub-retinal neovascularization with type 2A parafoveal telangiectasis. Am. J. Ophthalmol. 2005; 140:333335. [PubMed: 16086966]

Hutton WL, Snyder WB, Fuller D, Vaiser A. Focal parafoveal retinal telangiectasis. Arch. Ophthalmol. 1978; 96:1362-1367. [PubMed: 678172]

Isaacs TW, McAllister IL. Familial idiopathic juxtafoveolar retinal telangiectasis. Eye. 1996; 10(Pt 5): 639-642. [PubMed: 8977798]

Jaissle GB, May CA, van de Pavert SA, Wenzel A, Claes-May E, Giessl A, Szurman P, Wolfrum U, Wijnholds J, Fischer MD, Humphries P, Seeliger MW. Bone spicule pigment formation in retinitis pigmentosa: insights from a mouse model. Graefes Arch. Clin. Exp. Ophthalmol. 2010; 248:10631070. [PubMed: 20012642]

Jonas JB, Libondi T, von Baltz S, Beutelspacher S. Intravitreal bevacizumab for perifoveal telangiectasia. Acta Ophthalmol. 2011; 89:e607-e608. [PubMed: 20946328]

Jorge R, Costa RA, Calucci D, Scott IU. Intravitreal bevacizumab (Avastin) associated with the regression of subretinal neovascularization in idiopathic juxtafoveolar retinal telangiectasis. Graefes Arch. Clin. Exp. Ophthalmol. 2006; 245:1045-1048. [PubMed: 17136357]

Karagiannis D, Georgalas I, Ladas I, Eustratios P, Mitropoulos P. A case of subretinal neovascularization treated with intravitreal ranibizumab in a patient with idiopathic juxtafoveal retinal telangiectasis. Clin. Interv. Aging. 2009; 4:63-65. [PubMed: 19503767]

Kellner U, Kellner S. Klinik und Diagnostik der Zapfen-Dystrophien. Ophthalmologe. 2009; 106:99_ 108. [PubMed: 19190919]

Kiraly A, Nasemann JE. Idiopathische juxtafoveoläre Telangiektasien. Langzeitverlauf des Sehvermögens. Ophthalmologe. 1995; 92:698-703. [PubMed: 8751000]

Klein R, Blodi BA, Meuer SM, Myers CE, Chew EY, Klein BEK. The prevalence of macular telangiectasia type 2 in the Beaver Dam eye study. Am. J. Ophthalmol. 2010; 150:55-62. [PubMed: 20609708]

Koizumi H, Iida T, Maruko I. Morphologic features of group 2A idiopathic juxtafoveolar retinal telangiectasis in three-dimensional optical coherence tomography. Am. J. Ophthalmol. 2006; 142:340-343. [PubMed: 16876527]

Koizumi H, Cooney MJ, Leys A, Spaide RF. Centripetal retinal capillary proliferation in idiopathic parafoveolar telangiectasis. Br. J. Ophthalmol. 2007a; 91:1719-1720. [PubMed: 18024824]

Koizumi H, Slakter JS, Spaide RF. Full-thickness macular hole formation in idiopathic parafoveal telangiectasis. Retina. 2007b; 27:473-476. [PubMed: 17420701]

Konstantinidis L, Mantel I, Zografos L, Ambresin A. Intravitreal ranibizumab as primary treatment for neovascular membrane associated with idiopathic juxtafoveal retinal telangiectasia. Graefes Arch. Clin. Exp. Ophthalmol. 2009; 247:1567-1569. [PubMed: 19727795]

Kovach JL, Rosenfeld PJ. Bevacizumab (avastin) therapy for idiopathic macular telangiectasia type II. Retina. 2009; 29:27-32. [PubMed: 18936721]

Krivosic V, Tadayoni R, Massin P, Erginay A, Gaudric A. Spectral domain optical coherence tomography in type 2 idiopathic perifoveal telangiectasia. Ophthalmic Surg. Lasers Imaging. 2009; 40:379-384. [PubMed: 19634742]

Kurz-Levin MM, Halfyard AS, Bunce C, Bird AC, Holder GE. Clinical variations in assessment of bull's-eye maculopathy. Arch. Ophthalmol. 2002; 120:567-575. [PubMed: 12003605]

Lai CM, Dunlop SA, May LA, Gorbatov M, Brankov M, Shen WY, Binz N, Lai YK, Graham CE, Barry CJ, Constable IJ, Beazley LD, Rakoczy EP. Generation of transgenic mice with mild and severe retinal neovascularisation. Br. J. Ophthalmol. 2005; 89:911-916. [PubMed: 15965177] 
Lamoureux EL, Maxwell RM, Marella M, Dirani M, Fenwick E, Guymer RH. The longitudinal impact of macular telangiectasia (MacTel) type 2 on vision-related quality of life. Invest. Ophthalmol. Vis. Sci. 2011; 52:2520-2524. [PubMed: 21217104]

LaVail MM, Yasumura D, Matthes MT, Lau-Villacorta C, Unoki K, Sung CH, Steinberg RH. Protection of mouse photoreceptors by survival factors in retinal degenerations. Invest. Ophthalmol. Vis. Sci. 1998; 39:592-602. [PubMed: 9501871]

Lee BL. Bilateral subretinal neovascular membrane in idiopathic juxtafoveolar telangiectasis. Retina. 1996; 16:344-346. [PubMed: 8865399]

Lee HC, Liu M, Ho AC. Idiopathic juxtafoveal telangiectasis in association with celiac sprue. Arch. Ophthalmol. 2004; 122:411-413. [PubMed: 15006867]

Lee SW, Kim SM, Kim YT, Kang SW. Clinical features of idiopathic juxtafoveal telangiectasis in Koreans. Korean J. Ophthalmol. 2011; 25:225-230. [PubMed: 21860567]

Len AC, Powner MB, Zhu L, Hageman GS, Song X, Fruttiger M, Gillies MC. Pilot application of iTRAQ to the retinal disease Macular Telangiectasia. J. Proteome Res. 2012; 11:537-553. [PubMed: 22098468]

Leys A, Gilbert HD, Van De SW, Verougstraete C, Devriendt K, Lagae L, Gass JD. Familial spastic paraplegia and maculopathy with juxtafoveolar retinal telangiectasis and subretinal neovascularization. Retina. 2000; 20:184-189. [PubMed: 10783952]

Li KK, Goh TY, Parsons H, Chan WM, Lam DS. Use of intravitreal triamcinolone acetonide injection in unilateral idiopathic juxtafoveal telangiectasis. Clin. Experiment. Ophthalmol. 2005; 33:542544. [PubMed: 16181291]

Li B, Vachali P, Frederick JM, Bernstein PS. Identification of StARD3 as a lutein-binding protein in the macula of the primate retina. Biochemistry. 2011; 50:2541-2549. [PubMed: 21322544]

Liang FQ, Aleman TS, Dejneka NS, Dudus L, Fisher KJ, Maguire AM, Jacobson SG, Bennett J. Longterm protection of retinal structure but not function using RAAV.CNTF in animal models of retinitis pigmentosa. Mol. Ther. 2001; 4:461-472. [PubMed: 11708883]

Lira RP, Silva VB, Cavalcanti TM, de Souza AC, Pinto AP. Intravitreous ranibizumab as treatment for macular telangiectasia type 2. Arch. Ophthalmol. 2010; 128:1075-1078. [PubMed: 20697014]

Lowe MA, Akduman L, Olk RJ. Laser photocoagulation and glucose metabolism in idiopathic juxtafoveolar retinal telangiectasis. Ophthalmic Surg. Lasers. 1998; 29:126-139. [PubMed: 9507256]

Maberley DA, Yannuzzi LA, Gitter K, Singerman L, Chew E, Freund KB, Noguiera F, Sallas D, Willson R, Tillocco K. Radiation exposure: a new risk factor for idiopathic perifoveal telangiectasis. Ophthalmology. 1999; 106:2248-2252. [PubMed: 10599653]

MacDonald IM, Sauve Y, Sieving PA. Preventing blindness in retinal disease: ciliary neurotrophic factor intraocular implants. Can. J. Ophthalmol. 2007; 42:399-402. [PubMed: 17508034]

Maguluri S, Recchia CC, Recchia FM. Neurosensory macular detachment in group 2A juxtafoveolar telangiectasis and resolution following intravitreal triamcinolone. Retin. Cases Brief Rep. 2007; 1:20-21.

Mahajan VB, Russell SR, Stone EM. A new macular dystrophy with anomalous vascular development, pigment spots, cystic spaces, and neovascularization. Arch. Ophthalmol. 2009; 127:1449-1457. [PubMed: 19901210]

Maia Junior OO, Takahashi WY, Bonanomi MT, Nascimento VP, Melo CS. Injeção intravítrea de triancinolona no tratamento da telangiectasia retiniana justafoveolar idiopática. Arq. Bras. Oftalmol. 2006; 69:941-944. [PubMed: 17273694]

Maia Junior OO, Bonanomi MT, Takahashi WY, Nascimento VP, Takahashi BS. Intravitreal bevacizumab for foveal detachment in idiopathic perifoveal telangiectasia. Am. J. Ophthalmol. 2007; 144:296-299. [PubMed: 17659962]

Mandal S, Venkatesh P, Abbas Z, Vohra R, Garg S. Intravitreal bevacizumab (Avastin) for subretinal neovascularization secondary to type $2 \mathrm{~A}$ idiopathic juxtafoveal telangiectasia. Graefes Arch. Clin. Exp. Ophthalmol. 2007; 245:1825-1829. [PubMed: 17345090]

Mansour AM, Schachat A. Foveal avascular zone in idiopathic juxtafoveolar telangiectasia. Ophthalmologica. 1993; 207:9-12. [PubMed: 8278175] 
Margalit E, Apte RS, Sadda SR. Idiopathic parafoveal telangiectasis associated with a foveal pseudovitelliform lesion. Br. J. Ophthalmol. 2002; 86:1455-1456. [PubMed: 12446400]

Martinez JA. Intravitreal triamcinolone acetonide for bilateral acquired parafoveal telangiectasis. Arch. Ophthalmol. 2003; 121:1658-1659. [PubMed: 14609935]

Maruko I, Iida T, Sekiryu T, Fujiwara T. Early morphological changes and functional abnormalities in group 2A idiopathic juxtafoveolar retinal telangiectasis using spectral domain optical coherence tomography and microperimetry. Br. J. Ophthalmol. 2008; 92:1488-1491. [PubMed: 18703550]

Maruko I, Iida T, Sugano Y, Ojima A, Oyamada H, Sekiryu T. Demographic features of idiopathic macular telangiectasia in Japanese patients. Jpn. J. Ophthalmol. 2012; 56:152-158. [PubMed: 22219035]

Matsumoto Y, Yuzawa M. Intravitreal bevacizumab therapy for idiopathic macular telangiectasia. Jpn. J. Ophthalmol. 2010; 54:320-324. [PubMed: 20700800]

Matsumoto C, Arimura E, Okuyama S, Takada S, Hashimoto S, Shimomura Y. Quantification of metamorphopsia in patients with epiretinal membranes. Invest. Ophthalmol. Vis. Sci. 2003; 44:4012-4016. [PubMed: 12939323]

Matt G, Sacu S, Ahlers C, Schütze C, Dunavoelgyi R, Prager F, Prünte C, Schmidt-Erfurth U. Thirtymonth follow-up after intravitreal bevacizumab in progressive idiopathic macular telangiectasia type 2. Eye (Lond). 2010; 24:1535-1541. [PubMed: 20865030]

Mauget-Faysse M, Gambrelle J, Quaranta-El MM. Optical coherence tomography in tamoxifen retinopathy. Breast Cancer Res. Treat. 2006; 99:117-118. [PubMed: 16541311]

Mavrakanas N, Mendrinos E, Pournaras CJ, Salzmann J. Intravitreal ranibizumab and bevacizumab for bilateral subretinal neovascularization secondary to idiopathic juxtafoveal telangiectasia type $2 \mathrm{~A}$. Acta Ophthalmol. 2009; 87:930-932. [PubMed: 19706015]

Menchini U, Virgili G, Bandello F, Malara C, Rapizzi E, Lanzetta P. Bilateral juxtafoveolar telangiectasis in monozygotic twins. Am. J. Ophthalmol. 2000; 129:401-403. [PubMed: 10704569]

Michaelides M, Chen LL, Brantley MA Jr. Andorf JL, Isaak EM, Jenkins SA, Holder GE, Bird AC, Stone EM, Webster AR. ABCA4 mutations and discordant ABCA4 alleles in patients and siblings with bull's-eye maculopathy. Br. J. Ophthalmol. 2007; 91:1650-1655. [PubMed: 18024811]

Millay RH, Klein ML, Handelman IL, Watzke RC. Abnormal glucose metabolism and parafoveal telangiectasia. Am. J. Ophthalmol. 1986; 102:363-370. [PubMed: 3752203]

Moisseiev J, Lewis H, Bartov E, Fine SL, Murphy RP. Superficial retinal refractile deposits in juxtafoveal telangiectasis. Am. J. Ophthalmol. 1990; 109:604-605. [PubMed: 2333929]

Mondal S, Chattopadhyay A, Paul S. Intravitreal bevacizumab for the treatment of choroidal neovascularization secondary to idiopathic macular telangiectasia. Bengal Ophthalmic J. 2010:15-19.

Narayanan R, Chhablani J, Sinha M, Dave V, Tyagi M, Pappuru RR, Kuppermann BD. Efficacy of anti-vascular endothelial growth factor therapy in subretinal neovascularization secondary to macular telangiectasia type 2. Retina. 2012; 32:2001-2005. [PubMed: 22990322]

Nishijima K, Ng YS, Zhong L, Bradley J, Schubert W, Jo N, Akita J, Samuelsson SJ, Robinson GS, Adamis AP, Shima DT. Vascular endothelial growth factor-a is a survival factor for retinal neurons and a critical neuroprotectant during the adaptive response to ischemic injury. Am. J. Pathol. 2007; 171:53-67. [PubMed: 17591953]

Nishimura M, Taniguchi Y. Retinal vascular patterns in the macula and the perimacular area in premature and full-term infants. Ophthalmologica. 1982; 185:147-157. [PubMed: 7133629]

Oh KT, Park DW. Bilateral juxtafoveal telangiectasis in a family. Retina. 1999; 19:246-247. [PubMed: 10380032]

Okamoto N, Tobe T, Hackett SF, Ozaki H, Vinores MA, LaRochelle W, Zack DJ, Campochiaro PA. Transgenic mice with increased expression of vascular endothelial growth factor in the retina: a new model of intraretinal and subretinal neovascularization. Am. J. Pathol. 1997; 151:281-291. [PubMed: 9212753]

Olson JL, Mandava N. Macular hole formation associated with idiopathic parafoveal telangiectasia. Graefes Arch. Clin. Exp. Ophthalmol. 2006; 244:411-412. [PubMed: 16133029] 
Ooto S, Hangai M, Takayama K, Arakawa N, Tsujikawa A, Koizumi H, Oshima S, Yoshimura N. High-resolution photoreceptor imaging in idiopathic macular telangiectasia type 2 using adaptive optics scanning laser ophthalmoscopy. Invest. Ophthalmol. Vis. Sci. 2011; 52:5541-5550. [PubMed: 21642620]

Park D, Schatz H, McDonald HR, Johnson RN. Fibrovascular tissue in bilateral juxtafoveal telangiectasis. Arch. Ophthalmol. 1996; 114:1092-1096. [PubMed: 8790094]

Park DW, Schatz H, McDonald HR, Johnson RN. Grid laser photocoagulation for macular edema in bilateral juxtafoveal telangiectasis. Ophthalmology. 1997; 104:1838-1846. [PubMed: 9373114]

Parmalee NL, Schubert C, Merriam JE, Allikmets K, Bird AC, Gillies MC, Peto T, Figueroa M, Friedlander M, Fruttiger M, Greenwood J, Moss SE, Smith LE, Toomes C, Inglehearn CF, Allikmets R. Analysis of candidate genes for macular telangiectasia type 2. Mol. Vis. 2010; 16:2718-2726. [PubMed: 21179236]

Parmalee NL, Schubert C, Figueroa M, Bird AC, Peto T, Gillies MC, Bernstein PS, Kiryluk K, Terwilliger JD, Allikmets R. Identification of a potential susceptibility locus for macular telangiectasia type 2. PLoS One. 2012; 7:e24268. [PubMed: 22952568]

Parodi MB, Iacono P, Ravalico G. Subretinal neovascular membrane associated with type 2a idiopathic juxtafoveolar telangiectasis in pseudoxanthoma elasticum. Graefes Arch. Clin. Exp. Ophthalmol. 2006; 245:612-615. [PubMed: 16988836]

Patel B, Duvall J, Tullo AB. Lamellar macular hole associated with idiopathic juxtafoveolar telangiectasia. Br. J. Ophthalmol. 1988; 72:550-551. [PubMed: 3415948]

Potter MJ, Szabo SM, Chan EY, Morris AH. Photodynamic therapy of a subretinal neovascular membrane in type 2A idiopathic juxtafoveolar retinal telangiectasis. Am. J. Ophthalmol. 2002; 133:149-151. [PubMed: 11755857]

Potter MJ, Szabo SM, Sarraf D, Michels R, Schmidt-Erfurth U. Photodynamic therapy for subretinal neovascularization in type 2A idiopathic juxtafoveolar telangiectasis. Can. J. Ophthalmol. 2006; 41:34-37. [PubMed: 16462869]

Powner MB, Gillies MC, Tretiach M, Scott A, Guymer RH, Hageman GS, Fruttiger M. Perifoveal Müller cell depletion in a case of macular telangiectasia type 2. Ophthalmology. 2010; 117:2407-2416. [PubMed: 20678804]

Powner MB, Scott A, Zhu M, Munro PM, Foss AJ, Hageman GS, Gillies MC, Fruttiger M. Basement membrane changes in capillaries of the ageing human retina. Br. J. Ophthalmol. 2011; 95:13161322. [PubMed: 21606466]

Querques G, Coscas G, Soubrane G, Souied EH. Type II idiopathic macular telangiectasia and soft confluent drusen. Eur. J. Ophthalmol. 2010; 20:466-468. [PubMed: 19967665]

Reese A. Telangiectasis of the retina and Coats' disease. Am. J. Ophthalmol. 1956; 42:1-8. [PubMed: 13339898]

Rishi P, Shroff D, Rishi E. Combined photodynamic therapy and intravitreal ranibizumab as primary treatment for subretinal neovascular membrane (SRNVM) associated with type 2 idiopathic macular telangiectasia. Graefes Arch. Clin. Exp. Ophthalmol. 2008; 246:619-621. [PubMed: 18193448]

Roller AB, Folk JC, Patel NM, Boldt HC, Russell SR, Abramoff MD, Mahajan VB. Intravitreal bevacizumab for treatment of proliferative and nonproliferative type 2 idiopathic macular telangiectasia. Retina. 2011; 31:1848-1855. [PubMed: 21610563]

Roorda A, Romero-Borja F, Donnelly Iii W, Queener H, Hebert T, Campbell M. Adaptive optics scanning laser ophthalmoscopy. Opt. Express. 2002; 10:405-412. [PubMed: 19436374]

Ruys J, De Laey JJ, Vanderhaeghen Y, Van Aken EH. Intravitreal bevacizumab (Avastin) for the treatment of bilateral acquired juxtafoveal retinal telangiectasis associated with choroidal neovascular membrane. Eye (Lond). 2007; 21:1433-1434. [PubMed: 17693997]

Saint-Geniez M, Maharaj AS, Walshe TE, Tucker BA, Sekiyama E, Kurihara T, Darland DC, Young MJ, D'Amore PA. Endogenous VEGF is required for visual function: evidence for a survival role on Muller cells and photoreceptors. PLoS One. 2008; 3:e3554. [PubMed: 18978936]

Sallo FB, Leung I, Chung M, Wolf-Schnurrbusch UE, Dubra A, Williams DR, Clemons T, Pauleikhoff D, Bird AC, Peto T. Retinal crystals in type 2 idiopathic macular telangiectasia. Ophthalmology. 2011; 118:2461-2467. [PubMed: 21839520] 
Sallo FB, Leung I, Mathenge W, Kyari F, Kuper H, Gilbert CE, Bird AC, Peto T. The prevalence of type 2 idiopathic macular telangiectasia in two African populations. Ophthalmic Epidemiol. 2012a; 19:185-189. [PubMed: 22364548]

Sallo FB, Peto T, Egan C, Wolf-Schnurrbusch UE, Clemons TE, Gillies MC, Pauleikhoff D, Rubin GS, Chew EY, Bird AC. "En face" OCT imaging of the IS/OS junction line in type 2 idiopathic macular telangiectasia. Invest. Ophthalmol. Vis. Sci. 2012b; 53:6145-6152. [PubMed: 22899757]

Sarraf D, Ceron O, Rasheed K, Drenser KA, Casey R. West African crystalline maculopathy. Arch. Ophthalmol. 2003; 121:338-342. [PubMed: 12617703]

Sawa M, Gomi F, Ueno C, Suzuki M, Nishida K. Comparison of macular pigment in three types of macular telangiectasia. Graefes Arch. Clin. Exp. Ophthalmol. 2012 Epub ahead of print.

Schmitz-Valckenberg S, Fan K, Nugent A, Rubin GS, Peto T, Tufail A, Egan C, Bird AC, Fitzke FW. Correlation of functional impairment and morphological alterations in patients with group $2 \mathrm{~A}$ idiopathic juxtafoveal retinal telangiectasia. Arch. Ophthalmol. 2008; 126:330-335. [PubMed: 18332311]

Schmitz-Valckenberg S, Ong EE, Rubin GS, Peto T, Tufail A, Egan CA, Bird AC, Fitzke FW. Structural and functional changes over time in MacTel patients. Retina. 2009; 29:1314-1320. [PubMed: 19491718]

Shanmugam MP, Agarwal M. RPE atrophy following photodynamic therapy in type 2A idiopathic parafoveal telangiectasis. Indian J. Ophthalmol. 2005; 53:61-63. [PubMed: 15829751]

Shanmugam MP, Mythri HM, Shetty NS. Intravitreal bevacizumab for parafoveal telangiectasiaassociated choroidal neovascular membrane. Indian J. Ophthalmol. 2007; 55:490-491. [PubMed: 17951923]

Shen W, Zhang J, Chung SH, Hu Y, Ma Z, Gillies MC. Submacular DL-alpha-aminoadipic acid eradicates primate photoreceptors but does not affect luteal pigment or the retinal vasculature. Invest. Ophthalmol. Vis. Sci. 2011; 52:119-127. [PubMed: 20720223]

Shen W, Fruttiger M, Zhu L, Chung SH, Barnett NL, Kirk JK, Lee S, Coorey NJ, Killingsworth M, Sherman LS, Gillies MC. Conditional Müller Cell Ablation Causes Independent Neuronal and Vascular Pathologies in a Novel Transgenic Model. J. Neurosci. 2012; 32(45):15715-15727. [PubMed: 23136411]

Shukla D. Evolution and management of macular hole secondary to type 2 idiopathic macular telangiectasia. Eye (Lond). 2012; 25:532-533. [PubMed: 21252950]

Shukla D, Venkatesh R. Spontaneous closure of full-thickness macular hole in type 2 idiopathic macular telangiectasia. Graefes Arch. Clin. Exp. Ophthalmol. 2012; 250:1711-1712. [PubMed: 21938453]

Shukla D, Singh J, Kolluru CM, Kim R, Namperumalsamy P. Transpupillary thermotherapy for subfoveal neovascularization secondary to group 2A idiopathic juxtafoveolar telangiectasis. Am. J. Ophthalmol. 2004; 138:147-149. [PubMed: 15234300]

Siddiqui N, Fekrat S. Group 2A idiopathic juxtafoveolar retinal telangiectasia in monozygotic twins. Am. J. Ophthalmol. 2005; 139:568-570. [PubMed: 15767084]

Sieving PA, Caruso RC, Tao W, Coleman HR, Thompson DJ, Fullmer KR, Bush RA. Ciliary neurotrophic factor (CNTF) for human retinal degeneration: phase I trial of CNTF delivered by encapsulated cell intraocular implants. Proc. Natl. Acad. Sci. U. S. A. 2006; 103:3896-3901. [PubMed: 16505355]

Sigler EJ, Randolph JC, Calzada JI, Charles S. Comparison of observation, intravitreal bevacizumab, or pars plana vitrectomy for non-proliferative type 2 idiopathic macular telangiectasia. Graefes Arch. Clin. Exp. Ophthalmol. 2012 Epub ahead of print.

Smithen LM, Spaide RF. Photodynamic therapy and intravitreal triamcinolone for a subretinal neovascularization in bilateral idiopathic juxtafoveal telangiectasis. Am. J. Ophthalmol. 2004; 138:884-885. [PubMed: 15531339]

Snodderly DM, Auran JD, Delori FC. The macula pigment. II. Spatial distribution in primate retinas. Invest. Ophthalmol. Vis. Sci. 1984a; 25:674-685. [PubMed: 6724837] 
Snodderly DM, Brown PK, Delori FC, Auran JD. The macular pigment. I. Absorbance spectra, localization, and discrimination from other yellow pigments in primate retinas. Invest. Ophthalmol. Vis. Sci. 1984b; 25:660-673. [PubMed: 6724836]

Snyers B, Verougstraete C, Postelmans L, Leys A, Hykin P. Photodynamic therapy of subfoveal neovascular membrane in type $2 \mathrm{~A}$ idiopathic juxtafoveolar retinal telangiectasis. Am. J. Ophthalmol. 2004; 137:812-819. [PubMed: 15126144]

Stoffelns BM, Schoepfer K, Kramann C. Idiopathische makuläre Teleangiektasie (IMT) Verlaufsbeobachtung mit und ohne Laserphotokoagulation. Klin Monbl Augenheilkd. 2010; 227:252-256. [PubMed: 20408068]

Surguch V, Gamulescu MA, Gabel VP. Optical coherence tomography findings in idiopathic juxtafoveal retinal telangiectasis. Graefes Arch. Clin. Exp. Ophthalmol. 2006; 245:783-788. [PubMed: 17120013]

Szental JA, Baird PN, Richardson AJ, Islam FM, Scholl HP, Charbel Issa P, Holz FG, Gillies M, Guymer RH. Analysis of glutathione S-transferase Pi isoform (GSTP1) single-nucleotide polymorphisms and macular telangiectasia type 2. Int. Ophthalmol. 2010; 30:645-650. [PubMed: 20499266]

Takayama K, Ooto S, Tamura H, Yamashiro K, Otani A, Tsujikawa A, Yoshimura N. Intravitreal bevacizumab for type 1 idiopathic macular telangiectasia. Eye (Lond). 2010; 24:1492-1497. [PubMed: 20431610]

Takayama K, Ooto S, Tamura H, Yamashiro K, Otani A, Tsujikawa A, Yoshimura N. Retinal structural alterations and macular sensitivity in idiopathic macular telangiectasia type 1. Retina. 2012; 32:1973-1980. [PubMed: 22487581]

Tao W, Wen R, Goddard MB, Sherman SD, O'Rourke PJ, Stabila PF, Bell WJ, Dean BJ, Kauper KA, Budz VA, Tsiaras WG, Acland GM, Pearce-Kelling S, Laties AM, Aguirre GD. Encapsulated cell-based delivery of CNTF reduces photoreceptor degeneration in animal models of retinitis pigmentosa. Invest. Ophthalmol. Vis. Sci. 2002; 43:3292-3298. [PubMed: 12356837]

TAP-Study-Group. Photodynamic therapy of subfoveal choroidal neovascularization in age-related macular degeneration with verteporfin: one-year results of 2 randomized clinical trials-TAP report. Treatment of age-related macular degeneration with photodynamic therapy (TAP) Study Group. Arch. Ophthalmol. 1999; 117:1329-1345. [PubMed: 10532441]

Theelen T, Berendschot TT, Boon CJ, Hoyng CB, Klevering BJ. Analysis of visual pigment by fundus autofluorescence. Exp. Eye Res. 2008; 86:296-304. [PubMed: 18096158]

Tikellis G, Gillies MC, Guymer RH, McAllister IL, Shaw JE, Wong TY. Retinal vascular caliber and macular telangiectasia type 2. Ophthalmology. 2009; 116:319-323. [PubMed: 19187824]

Tobe T, Okamoto N, Vinores MA, Derevjanik NL, Vinores SA, Zack DJ, Campochiaro PA. Evolution of neovascularization in mice with over-expression of vascular endothelial growth factor in photoreceptors. Invest. Ophthalmol. Vis. Sci. 1998; 39:180-188. [PubMed: 9430560]

Toy BC, Koo E, Cukras C, Meyerle CB, Chew EY, Wong WT. Treatment of nonneovascular idiopathic macular telangiectasia type 2 with intrevitreal ranibizumab: results of a phase 2 clinical trial. Retina. 2012; 32:996-1006. [PubMed: 22266930]

Trauzettel-Klosinski S. Reading disorders due to visual field defects: a neuroophthalmological view. Neuro-Ophthalmology. 2002; 27:79-90.

Trieschmann M, van Kuijk FJ, Alexander R, Hermans P, Luthert P, Bird AC, Pauleikhoff D. Macular pigment in the human retina: histological evaluation of localization and distribution. Eye. 2008; 22:132-137. [PubMed: 17401321]

van der Veen RL, Fuijkschot J, Willemsen MA, Cruysberg JR, Berendschot TT, Theelen T. Patients with Sjogren-Larsson syndrome lack macular pigment. Ophthalmology. 2010; 117:966-971. [PubMed: 20163870]

van Eeden PE, Tee LB, Lukehurst S, Lai CM, Rakoczy EP, Beazley LD, Dunlop SA. Early vascular and neuronal changes in a VEGF transgenic mouse model of retinal neovascularization. Invest. Ophthalmol. Vis. Sci. 2006; 47:4638-4645. [PubMed: 17003462]

Vianna RN, Squeri G, Turquetti R, Brasil OF, Burnier MN Jr. Intravitreal pegaptanib reduces fluorescein leakage in idiopathic parafoveal telangiectasis. Can. J. Ophthalmol. 2008; 43:492493. [PubMed: 18711476] 
Watzke RC, Klein ML, Folk JC, Farmer SG, Munsen RS, Champfer RJ, Sletten KR. Long-term juxtafoveal retinal telangiectasia. Retina. 2005; 25:727-735. [PubMed: 16141860]

Weber BH, Schrewe H, Molday LL, Gehrig A, White KL, Seeliger MW, Jaissle GB, Friedburg C, Tamm E, Molday RS. Inactivation of the murine X-linked juvenile retinoschisis gene, Rs 1h, suggests a role of retinoschisin in retinal cell layer organization and synaptic structure. Proc. Natl. Acad. Sci. U. S. A. 2002; 99:6222-6227. [PubMed: 11983912]

Whitehead AJ, Mares JA, Danis RP. Macular pigment: a review of current knowledge. Arch. Ophthalmol. 2006; 124:1038-1045. [PubMed: 16832030]

Willemsen MA, Cruysberg JR, Rotteveel JJ, Aandekerk AL, Van Domburg PH, Deutman AF. Juvenile macular dystrophy associated with deficient activity of fatty aldehyde dehydrogenase in SjogrenLarsson syndrome. Am. J. Ophthalmol. 2000; 130:782-789. [PubMed: 11124298]

Windisch R, Kozousek V. Intravitreal bevacizumab compared with photodynamic therapy with verteporfin for group 2a parafoveal retinal telangiectasis. Can. J. Ophthalmol. 2008; 43:489-490. [PubMed: 18711474]

Wong WT, Forooghian F, Majumdar Z, Bonner RF, Cunningham D, Chew EY. Fundus autofluorescence in type 2 idiopathic macular telangiectasia: correlation with optical coherence tomography and microperimetry. Am. J. Ophthalmol. 2009; 148:573-583. [PubMed: 19573860]

Wu L, Evans T, Arevalo JF, Berrocal MH, Rodriguez FJ, Hsu M, Sanchez JG. Long-term effect of intravitreal triamcinolone in the nonproliferative stage of type II idiopathic parafoveal telangiectasia. Retina. 2008; 28:314-319. [PubMed: 18301037]

Yannuzzi, LA. The Retinal Atlas. Saunders Elsevier; 2010.

Yannuzzi LA, Bardal AM, Freund KB, Chen KJ, Eandi CM, Blodi B. Idiopathic macular telangiectasia. Arch. Ophthalmol. 2006; 124:450-460. [PubMed: 16606869]

Zeimer MB, Kromer I, Spital G, Lommatzsch A, Pauleikhoff D. Macular telangiectasia: patterns of distribution of macular pigment and response to supplementation. Retina. 2010a; 30:1282-1293. [PubMed: 20671587]

Zeimer MB, Padge B, Heimes B, Pauleikhoff D. Idiopathic macular telangiectasia type 2: distribution of macular pigment and functional investigations. Retina. 2010b; 30:586-595. [PubMed: 20386096] 


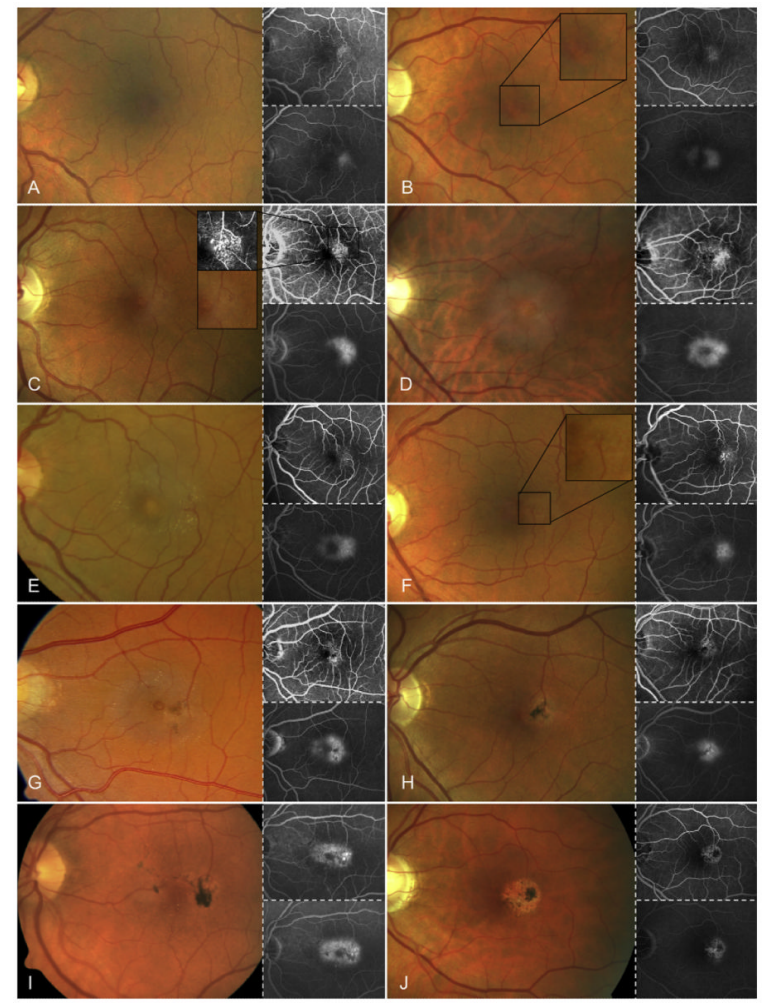

Fig. 1.

Clinical findings and corresponding early (respective upper frame) and late (respective lower frame) fluorescein angiography in patients with MacTel type 2. All findings are most pronounced temporal to the foveola, but may encompass a central oval area. Staging is used according to the Gass \& Blodi classification. A,B) Stage 1 with only mild angiographic leakage and no typical funduscopic findings. C,D) Stage 2 with loss of retinal transparency ("retinal graying") C) only temporal to the foveola or D) within the entire paracentral area. E) Foveal yellow spot in a stage 2 eye with pronounced crystalline deposits. F) Stage 3 with a blunted retinal venule. G-J) Stage 4 with various manifestations of pigment proliferation. G) Early pigmentations; note also the pseudo-lamellar hole, the graying and the crystalline deposits. H) Pigment proliferation without obvious other findings characteristic for MacTel type 2. I,J) Retinal pigment proliferations with different degrees of surrounding RPEatrophy. Some graying and crystalline deposits are seen in I). 

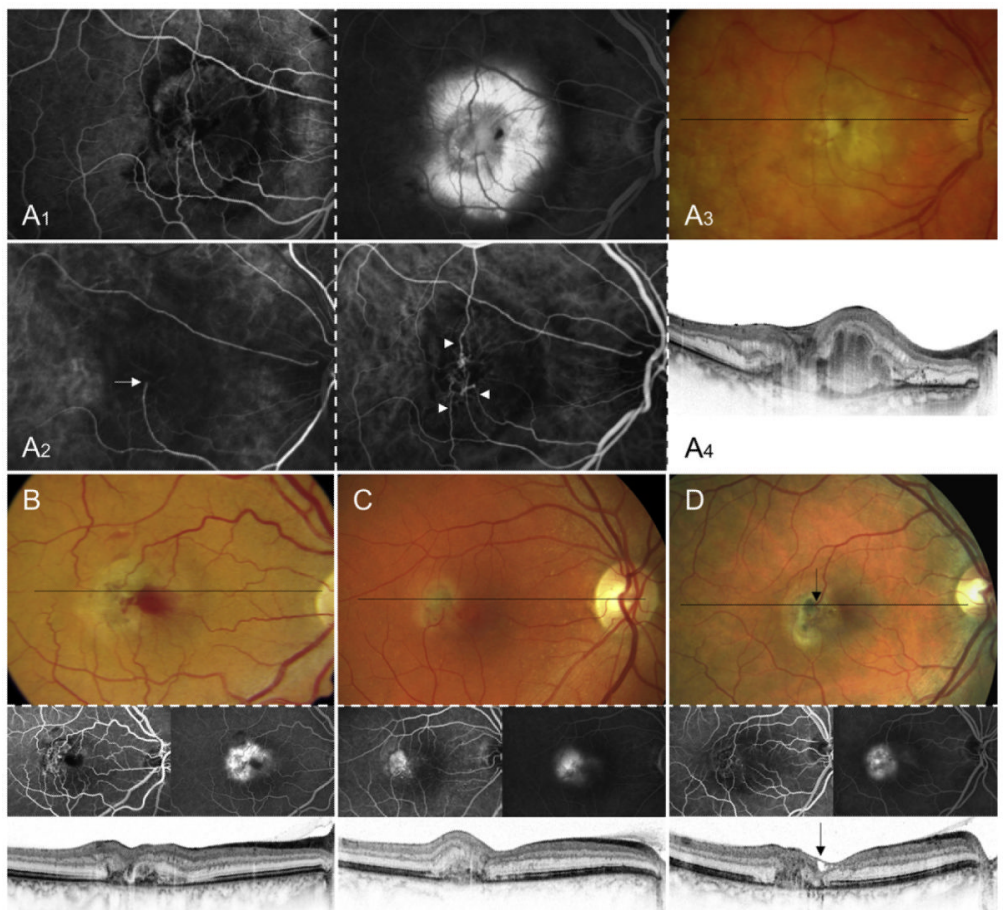

Fig. 2.

Neovascular complexes originating from the retinal vasculature may occur at any disease stage. A) Fluorescein (A1) and indocyanine green (A2) angiography of a large neovascular complex (left: early angiographic frames; middle: late frames). There is some fibrotic appearance (A3) and relatively little intraretinal exudation (A4). The arrow (A2) marks the arterial feeding vessel and the arrow heads mark draining venules of a neovascular complex. B-D) Active neovascular membrane with foveal hemorrhage (B), early (C) and late (D) phases of a fibrotic stage with pigmentation. There is remarkably little exudation and no cystoid edema or subretinal fluid. The arrows (D) mark corresponding positions. 


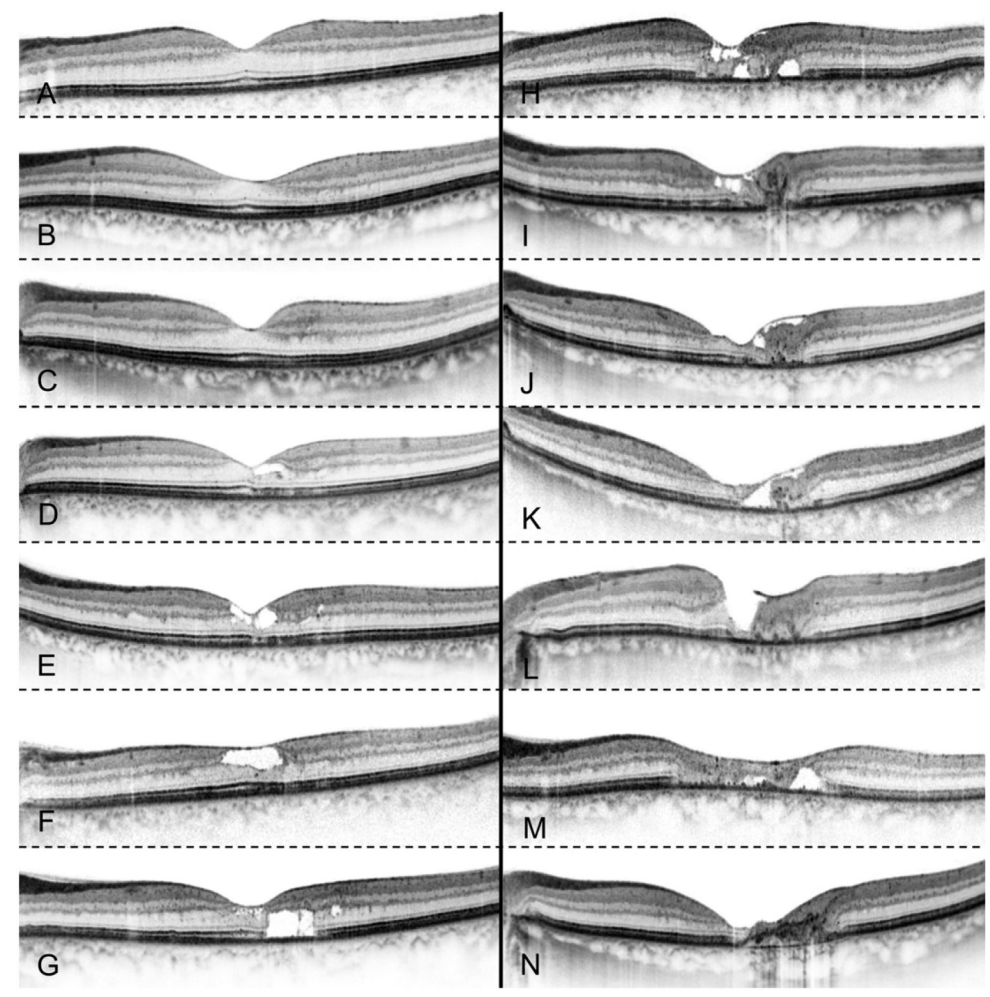

Fig. 3.

Phenotypic findings on spectral domain OCT imaging in patients with MacTel type 2. The optic nerve head is always to the left side in each of these horizontal scans through the foveal center. A) Normal retina. B) An asymmetric foveal contour may occur very early in the disease. C) Hyperreflectivity within the inner retinal layers due to capillary leakage may also be an early finding. D-F) Hyporeflective cavities within the inner foveal layers may remain without marked functional loss. There is some discontinuity of the highly reflective line above the retinal pigment epithelium and thinning of the outer nuclear layer mainly centrally and temporal to the foveal center. G) Hyporeflective cavities within the outer retina. H) Collapse of such outer retinal cavities. E-J) Atrophic outer retina with hyperreflective pigment plaques. $\mathbf{J}-\mathbf{K}$ ) The inner retinal layers appear to detach from the inner limiting membrane. L) A lamellar macular hole may develop after disruption of the inner limiting membrane. M-N) Localized complete atrophy of the outer retina with reactive pigment epithelial proliferation $(\mathbf{N})$. 


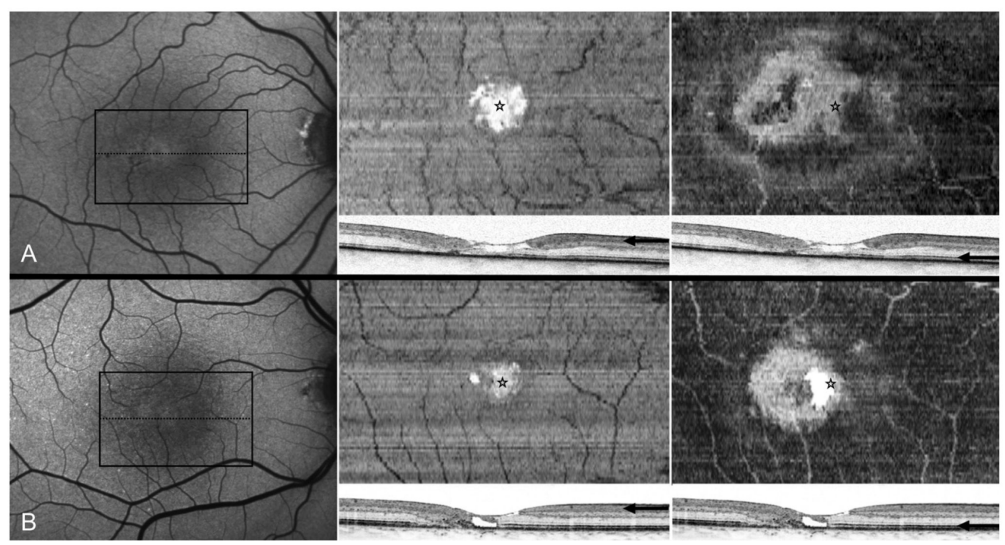

Fig. 4.

"En Face"-view of OCT volume-scans. The left image shows the correspondent fundus autofluorescence, the black box indicating the position of the volume scan. The dotted line indicates the position of the B-scan shown in the middle and right image. The asterisk marks the foveal center. The arrow marks the position of the en-face image. The middle images are aligned parallel to the inner limiting membrane to show the inner retinal layers. There is a round hole centered on the foveola. The right images are aligned along the RPE band and show the topographic distribution of the disruption of the line representing the inner segmenteouter segment border of the photoreceptors. In patient $\mathbf{A}$, the area of altered reflectivity within the inner segment-outer segment border corresponds to the entire retinal area affected by disease, whereas in patient $\mathbf{B}$, this area is more confined to an area centered temporal to the foveola. 


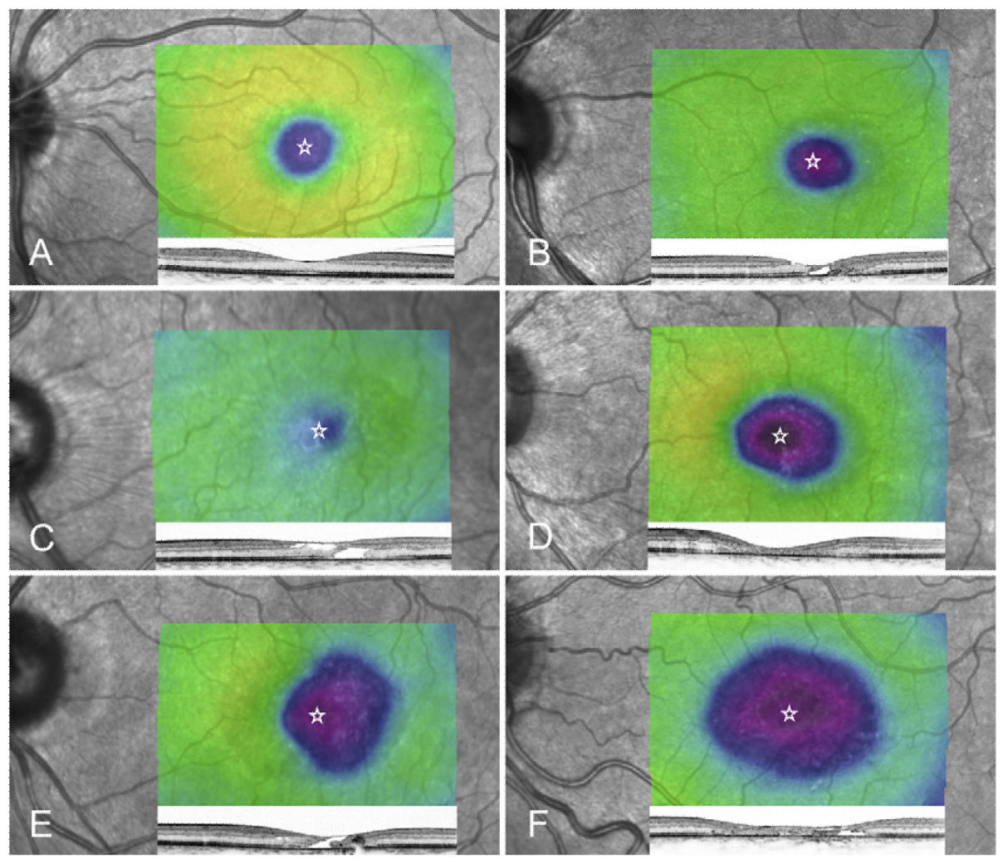

Fig. 5.

Retinal thickness maps in an age-matched normal control (A) and patients with MacTel type 2 (B-F), representing the phenotypic variability. The B-scan underneath each thickness map was recorded through the foveal center (marked by an asterisk). Overall, there is an asymmetry of the foveal depression, a loss of retinal contour, and a general thinning of the macular area. In later disease stages, there is pronounced retinal thinning due to outer retinal atrophy. 


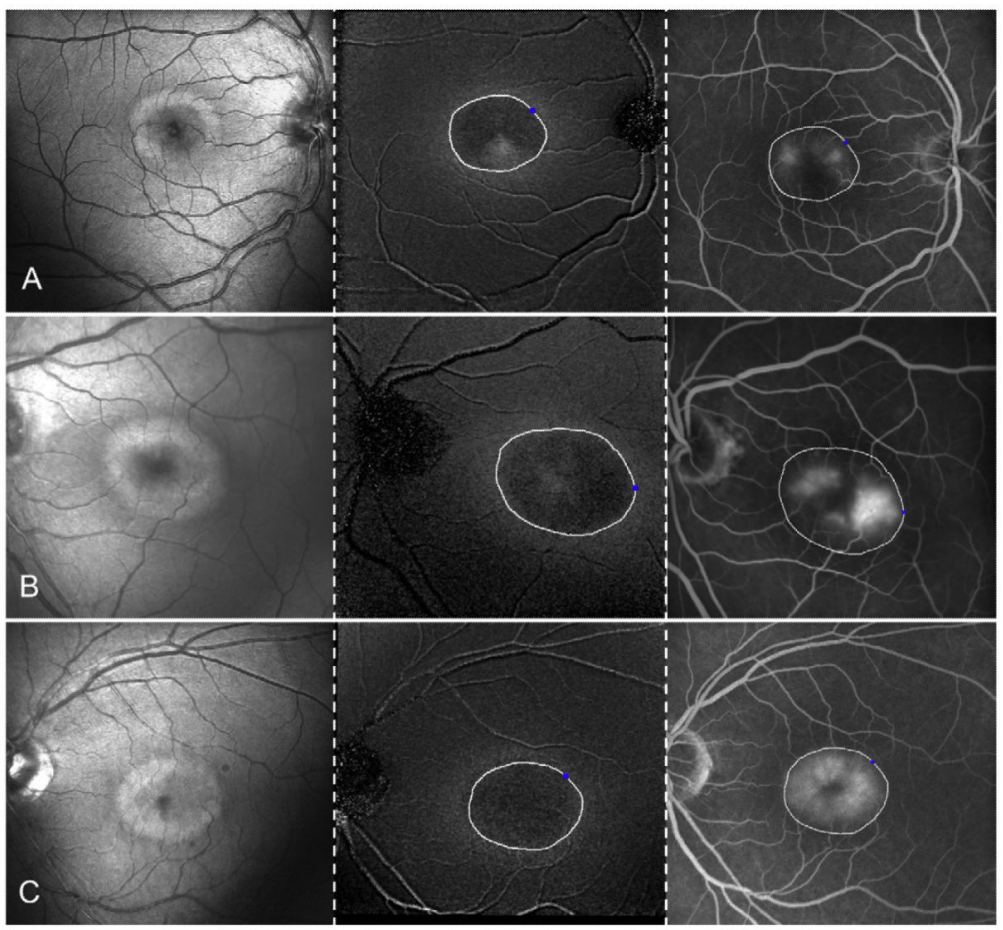

Fig. 6.

Confocal blue reflectance imaging (left) shows a highly reflective oval areas that correspond to loss of blue light-absorbing lutein and zeaxanthin on macular pigment maps (middle). Fluorescein angiography reveals leakage within a smaller area than that of macular pigment loss. The white line delineates the area of increased blue reflectance. Examples of three individual patients are shown (A-C). A representative normal confocal blue reflectance image can be found in Charbel Issa et al., 2008a, Fig. 1A. A representative normal macular pigment distribution is shown in Fig. 7B. 


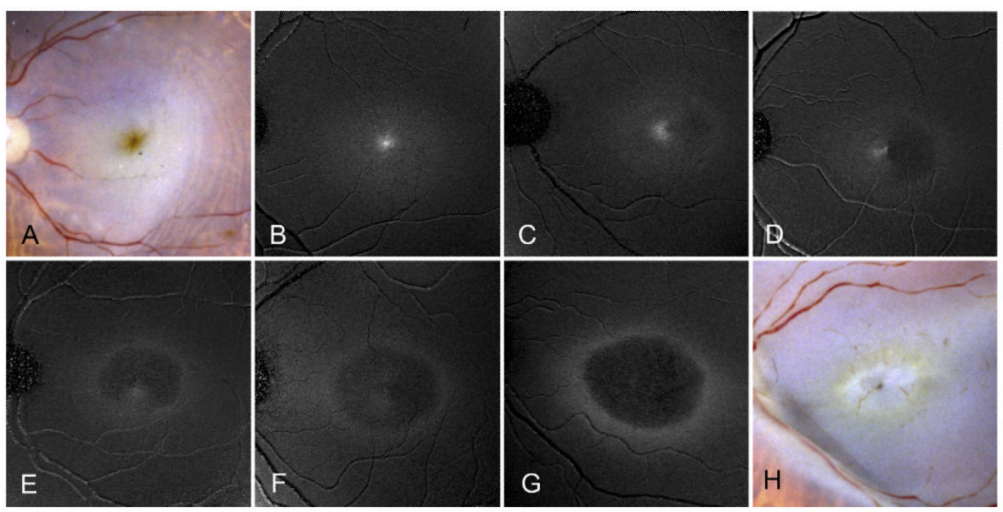

Fig. 7.

Macular pigment distribution in a normal eye (B) and at various stages in eyes with MacTel type $2-(\mathbf{C}-\mathbf{G})$. Macular pigment loss may be very subtle only affecting a wedge-shaped area temporal to the foveal center $(\mathbf{C}, \mathbf{D})$, may encompass a larger area with some degree of central/nasal sparing, or may encompass an oval area centered on the fovea. The postmortem photographs show the normal macular pigment distribution with the highest peak centrally in an unaffected eye (A) and the ring like distribution with central loss of macular pigment in an eye with MacTel type $2(\mathbf{H})$. The post-mortem photographs $(\mathrm{A}, \mathrm{H})$ were kindly provided by Dr. Gregory Hageman. 


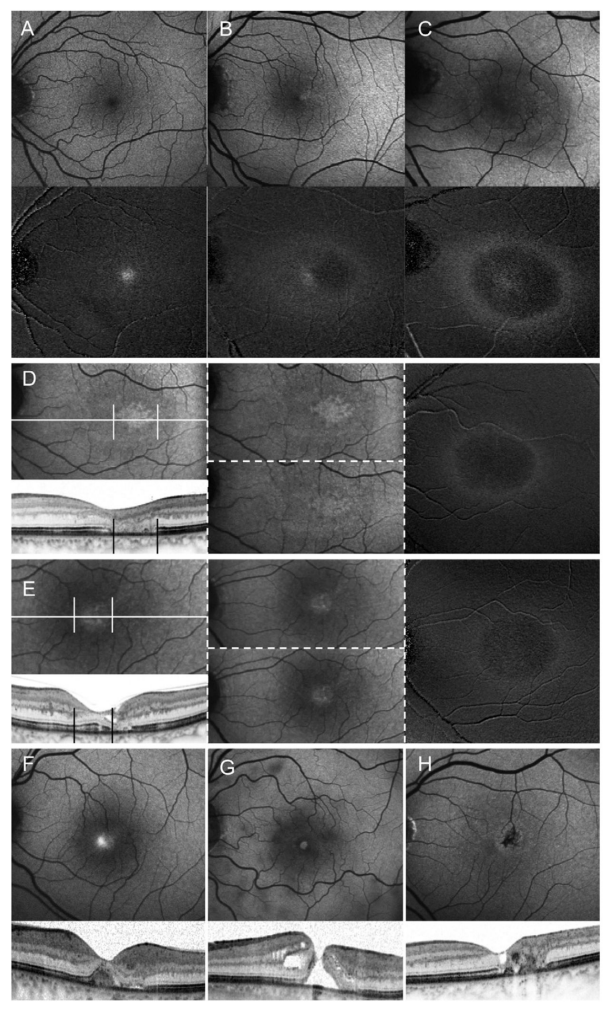

Fig. 8.

Fundus autofluorescence (AF; excitation at $488 \mathrm{~nm}$ ) imaging in MacTel type 2. AF imaging may reveal increased signals (B-G) compared to normal (A) for various reasons. B,C) Where macular pigment (lower images) is decreased, there is usually a lack of the normal foveal masking of the AF signal (upper image) by macular pigment, which absorbs the blue excitation light. D) Another reason for an increased AF signal in MacTel type 2 may be the loss of photoreceptors and therefore less absorption of the excitation light by photopigment. Unbleached photopigment in the surrounding area absorbs blue light and therefore decreases the AF signal (left). OCT confirms atrophy of the photoreceptor layer (marked by vertical bars). After bleaching the photopigment with the excitation light for $1 \mathrm{~min}$, the contrast between areas of preserved and those with lost photopigment decreases; compare the upper (before bleaching) and lower (after bleaching) images of the middle panel. In this case, bleaching of the surrounding photopigment reduces the contrast between the area of preserved photoreceptors and the area of photoreceptor loss. Note the different area of macular pigment loss (right) in the same eye. E) The same recordings as in D), but in an eye where the increased signal is not due to loss of macular pigment or photoreceptors, but rather appears to originate from additional subfoveal fluorophores. F) A similar phenomenon as in E), but more pronounced (same patient as in Fig. 1E with strong fluorescence of the yellow spot). G) Increased AF due to a full thickness macular hole. H) A decreased fundus AF signal due to blockage by pigment plaques (same patient as in Fig. $1 \mathrm{H})$. 


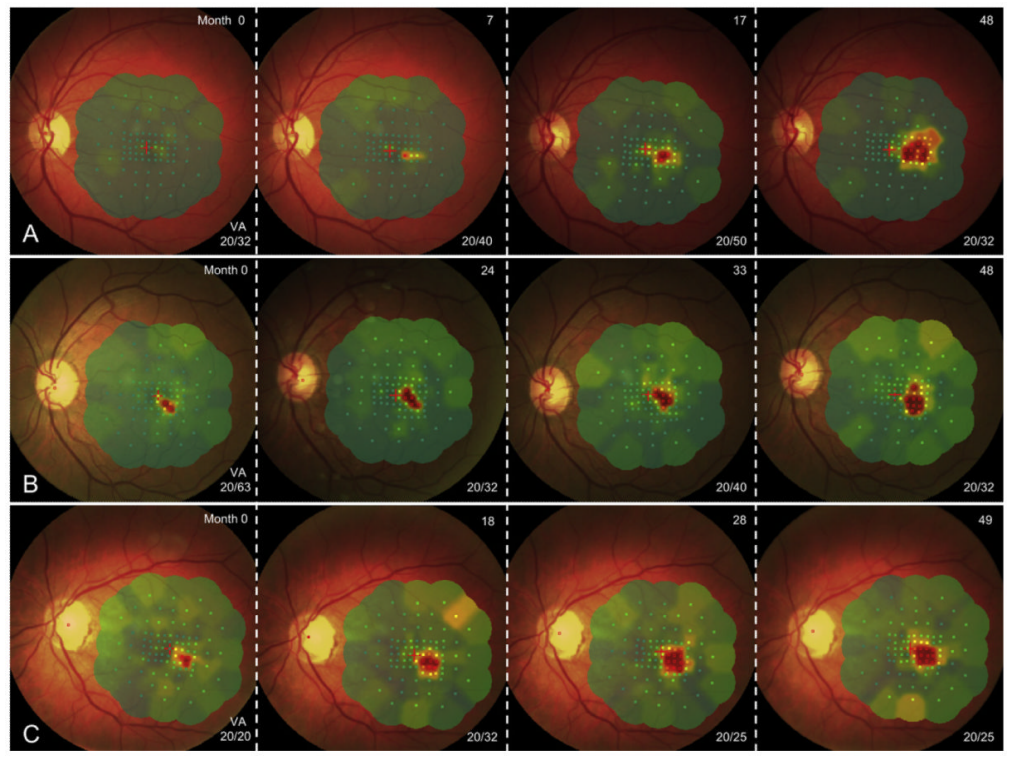

Fig. 9.

Microperimetry in 3 different patients (rows A-C) with MacTel type 2 over a 4-year-follow up. Absolute scotoma temporal to the fovea (deep red color) progresses considerably, whereas visual acuity (VA) remains largely stable. 


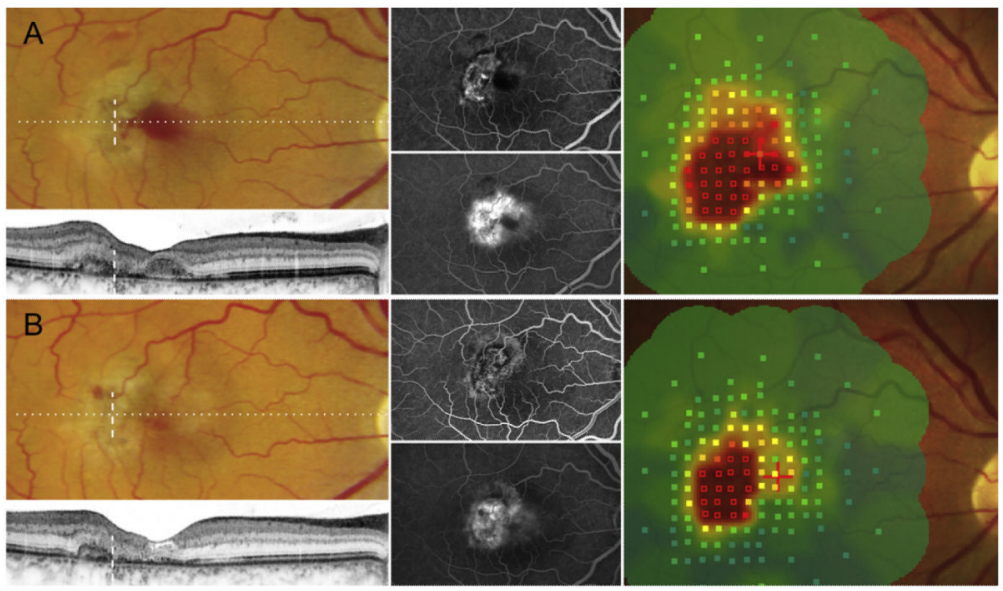

Fig. 10.

Effects of intravitreal bevacizumab therapy in neovascular MacTel type 2. A) Findings at baseline visit: Foveal hemorrhage in funduscopy (left, cf. Fig. 2B), due to neovascular membrane with leakage in fluorescein angiography (top, early phase; bottom, late phase). In microperimetry, there is a large absolute scotoma which encompasses the foveal center. Four months after one single treatment with intravitreal bevacizumab $(\mathbf{B})$, the hemorrhage had been resorbed and leakage was reduced. The foveal center after treatment shows only a relative defect and visual acuity has improved from 20/80 to 20/50. 


\section{Table 1}

Summary of clinical findings in macular telangiectasia without known cause according to the classification by Gass and Blodi (1993).

\begin{tabular}{|c|c|c|c|c|c|}
\hline Clinical findings/origin & Gender predominance & Mean age & Group & Sub-type & \\
\hline \multirow{2}{*}{$\begin{array}{l}\text { Unilateral, visible telangiectasia, } \\
\text { macular edema, hard exudates/ } \\
\text { considered developmental anomaly }\end{array}$} & \multirow[t]{2}{*}{ Males } & \multirow[t]{2}{*}{40} & \multirow[t]{2}{*}{1} & A & Involved area $>2$ clock hours \\
\hline & & & & B & Involved area $\leq 2$ clock hours \\
\hline \multirow{6}{*}{$\begin{array}{l}\text { Bilateral, occult telangiectasia, } \\
\text { minimal exudation, foveolar atrophy, } \\
\text { superficial retinal crystalline deposits/ } \\
\text { considered to be acquired }\end{array}$} & \multirow[t]{6}{*}{ Males $=$ females } & \multirow[t]{5}{*}{$50-60$} & \multirow[t]{5}{*}{2} & \multirow[t]{5}{*}{$\begin{array}{l}\text { A }(=\text { MacTel } \\
\text { type } 2)\end{array}$} & $\begin{array}{l}\text { Stage } 1 \text { Diffuse } \\
\text { hyperfluorescence in late phase } \\
\text { fluorescein angiography }\end{array}$ \\
\hline & & & & & $\begin{array}{l}\text { Stage } 2 \text { Reduced parafoveolar } \\
\text { retinal transparency }\end{array}$ \\
\hline & & & & & $\begin{array}{l}\text { Stage } 3 \text { Dilated right angled } \\
\text { venules }\end{array}$ \\
\hline & & & & & $\begin{array}{l}\text { Stage } 4 \text { Intraretinal pigment } \\
\text { clumping }\end{array}$ \\
\hline & & & & & Stage 5 Vascular membranes \\
\hline & & $\sim 10$ & & $\mathrm{~B}$ & Juvenile familiar \\
\hline \multirow{2}{*}{$\begin{array}{l}\text { Bilateral, visible telangiectasia, } \\
\text { minimal exudation, progressive } \\
\text { obliteration of the perifoveolar } \\
\text { capillary network capillary occlusion, } \\
\text { optic disc pallor/considered to be } \\
\text { acquired }\end{array}$} & \multirow[t]{2}{*}{ Inconclusive } & \multirow[t]{2}{*}{50} & \multirow[t]{2}{*}{3} & A & \\
\hline & & & & B & Additional CNS-vasculopathy \\
\hline
\end{tabular}

Prog Retin Eye Res. Author manuscript; available in PMC 2014 May 01. 


\section{Table 2}

Prevalence of macular alterations in patients with macular telangiectasia type 2 . The frequency indicated in the left column is based on clinical experience. Percentages in the middle and right columns are based on analysis of fundus photographs of the two largest patient cohorts reported (Clemons et al., 2010; Gass and Blodi, 1993). The frequency of these clinical findings in other reported cohorts may vary depending on the distribution of disease stages in the studied cohort. Neovascular complex may be associated with hemorrhage, cystoid edema, exudates, and eventually scarring.

\begin{tabular}{llll}
\hline Funduscopic sign & Frequency & & \\
\cline { 2 - 4 } & Clin. exp. & Gass \& Blodi & MacTel study \\
\hline Lack of foveolar reflex & Frequent & n.r. & n.r. \\
Reduced retinal transparency (graying) & Frequent & n.r. & $74 \%$ \\
Crystalline deposits & Frequent & $38 \%$ & $21 \%$ \\
Ectatic capillaries & Frequent & $64 \%$ & $51 \%$ \\
Blunted/dilated retinal vessel & Medium ${ }^{*}$ & $34 \%$ & $29 \% / 25 \%$ \\
Foveal atrophy & Medium ${ }^{*}$ & $13 \%$ & n.r. \\
Pigment-hypertrophy & Medium & $41 \%$ & $33 \%$ \\
Yellow foveal spot & Rare & $3 \%$ & n.r. \\
Retinal hemorrhage in absence of a neovascular complex & Rare & n.r. & n.r. \\
Atrophy of the RPE & Rare & n.r. & n.r. \\
Lamellar or full thickness macular hole & Rare & n.r. & n.r. \\
Neovascular complex & Rare & $14 \%$ & $2 \%$ \\
\hline
\end{tabular}

n.r. = not reported.

Frequent in late disease stages; 
Table 3

Findings on OCT imaging in patients with macular telangiectasia type 2.

\begin{tabular}{ll}
\hline Optical coherence tomography & Frequent \\
\hline Hyporeflective cavities of the inner and outer neurosensory retina & Frequent \\
Normal or subnormal retinal thickness despite angiographic leakage & Frequent \\
Disruption of the border between inner and outer photoreceptor segments & Frequent \\
Increased reflectivity of inner neurosensory layers & Frequent \\
Hyperreflective intra- or subretinal lesions (pigment migration or neovascular membranes) in late disease stages & Frequent \\
Outer neurosensory atrophy in late disease stages & Rare \\
Foveal detachment & Rare \\
Lamellar or full thickness macular holes & Rare \\
\hline Subfoveal debris accumulation &
\end{tabular}


Table 4

Overview of reported treatment approaches for non-proliferative and neovascular MacTel type 2.

\begin{tabular}{|c|c|c|c|c|}
\hline & \multicolumn{2}{|l|}{ Non-proliferative } & \multicolumn{2}{|l|}{ Neovascular } \\
\hline & Conclusion & References & Conclusion & References \\
\hline $\begin{array}{l}\text { Focal argon laser } \\
\text { photocoagulation }\end{array}$ & $\begin{array}{l}\text { No improvement or } \\
\text { stabilization. } \\
\text { Potentially worsens the } \\
\text { disease course and } \\
\text { potentially induces } \\
\text { development of } \\
\text { neovascular membranes. }\end{array}$ & $\begin{array}{l}\text { (Chopdar, 1978; } \\
\text { Friedman et al., 1993; } \\
\text { Gass and Blodi, 1993; } \\
\text { Hutton et al., 1978; } \\
\text { Kiraly and Nasemann, } \\
\text { 1995; Lowe et al., 1998; } \\
\text { Park et al., 1997; } \\
\text { Stoffelns et al., 2010; } \\
\text { Watzke et al., 2005) }\end{array}$ & $\begin{array}{l}\text { Obsolete due to side } \\
\text { effects }\end{array}$ & $\begin{array}{l}\text { (Gass and Blodi, 1993; } \\
\text { Lee, 1996; Watzke et al., } \\
\text { 2005) }\end{array}$ \\
\hline Photodynamic therapy (PDT) & No beneficial effects & $\begin{array}{l}\text { (De Lahitte et al., 2004; } \\
\text { Windisch and Kozousek, } \\
\text { 2008) }\end{array}$ & $\begin{array}{l}\text { Apparently } \\
\text { beneficial. } \\
\text { Larger studies } \\
\text { lacking. }\end{array}$ & $\begin{array}{l}\text { (Hershberger et al., } \\
\text { 2003; Hussain et al., } \\
\text { 2005; Potter et al., 2002; } \\
\text { Potter et al., 2006; } \\
\text { Shanmugam and } \\
\text { Agarwal, 2005; Snyers } \\
\text { et al., 2004; Watzke et } \\
\text { al., 2005) }\end{array}$ \\
\hline + Intravitreal steroids & - & - & $\begin{array}{l}\text { May support the } \\
\text { effect of PDT }\end{array}$ & $\begin{array}{l}\text { (Smithen and Spaide, } \\
\text { 2004) }\end{array}$ \\
\hline + Intravitreal VEGF inhibition & - & - & & $\begin{array}{l}\text { (Rishi et al., 2008; Ruys } \\
\text { et al., 2007) }\end{array}$ \\
\hline Intravitreal steroids & $\begin{array}{l}\text { Not clearly beneficial, } \\
\text { fading effect over time, } \\
\text { potential side effects. } \\
\text { Possible positive effect in } \\
\text { eyes with foveal } \\
\text { detachment. }\end{array}$ & $\begin{array}{l}\text { (Alldredge and } \\
\text { Garretson, 2003; Cakir } \\
\text { et al., 2006; Maguluri et } \\
\text { al., 2007; Maia Junior et } \\
\text { al., 2006; Martinez, } \\
\text { 2003; Wu et al., 2008) }\end{array}$ & - & - \\
\hline $\begin{array}{l}+ \text { Indocyanine green-mediated } \\
\text { photothrombosis }\end{array}$ & & (Arevalo et al., 2007) & & \\
\hline $\begin{array}{l}\text { Posterior juxtascleral } \\
\text { administration of steroids }\end{array}$ & No clear beneficial effects & (Eandi et al., 2006) & May be beneficial & (Eandi et al., 2006) \\
\hline Intravitreal VEGF inhibition & $\begin{array}{l}\text { In short term pronounced } \\
\text { anatomical normalization } \\
\text { and functional } \\
\text { improvement. However, } \\
\text { atrophic alterations may } \\
\text { progress nonetheless. } \\
\text { Possible positive effect in } \\
\text { eyes with foveal } \\
\text { detachment. }\end{array}$ & $\begin{array}{l}\text { (Charbel Issa et al., } \\
\text { 2008c; Charbel Issa et } \\
\text { al., 2011; Charbel Issa et } \\
\text { al., 2007b; Charbel Issa } \\
\text { et al., 2007d; Charbel } \\
\text { Issa et al., 2010; } \\
\text { Gamulescu et al., 2008; } \\
\text { Jonas et al., 2011; } \\
\text { Kovach and Rosenfeld, } \\
\text { 2009; Lira et al., 2010; } \\
\text { Maia Junior et al., 2007; } \\
\text { Matsumoto and Yuzawa, } \\
\text { 2010; Matt et al., 2010; } \\
\text { Roller et al., 2011; Toy } \\
\text { et al., 2012; Vianna et } \\
\text { al., 2008; Windisch and } \\
\text { Kozousek, 2008) }\end{array}$ & $\begin{array}{l}\text { Apparently } \\
\text { beneficial. Larger } \\
\text { and long term } \\
\text { studies lacking. }\end{array}$ & $\begin{array}{l}\text { (Charbel Issa et al., } \\
\text { 2007b; Jorge et al., } \\
\text { 2006; Karagiannis et al., } \\
\text { 2009; Konstantinidis et } \\
\text { al., 2009; Maia Junior et } \\
\text { al., 2007; Mandal et al., } \\
\text { 2007; Mavrakanas et al., } \\
\text { 2009; Mondal et al., } \\
\text { 2010; Narayanan et al., } \\
\text { 2012; Roller et al., 2011; } \\
\text { Ruys et al., 2007; } \\
\text { Shanmugam et al., 2007) }\end{array}$ \\
\hline Transpupillary thermotherapy & - & - & May be beneficial & (Shukla et al., 2004) \\
\hline Vitreoretinal surgery & $\begin{array}{l}\text { Vitrectomy with internal } \\
\text { limiting membrane } \\
\text { removal not effective }\end{array}$ & (Sigler et al., 2012) & $\begin{array}{l}\text { Surgical membrane } \\
\text { removal obsolete }\end{array}$ & $\begin{array}{l}\text { (Berger et al., 1997; } \\
\text { Davidorf et al., 2004) }\end{array}$ \\
\hline
\end{tabular}

Prog Retin Eye Res. Author manuscript; available in PMC 2014 May 01. 